This document is the accepted manuscript version of the following article:Dietzel, A., Mieleitner, J., Kardaetz, S., \& Reichert, P. (2013). Effects of changes in the driving forces on water quality and plankton dynamics in three Swiss lakes - long-term simulations with BELAMO. Freshwater Biology, 58(1), 10-35. http://doi.org/10.1111/fwb.12031

\title{
Effects of changes in the driving forces on water quality and plankton dynamics in three Swiss lakes - long-term simulations with BELAMO
}

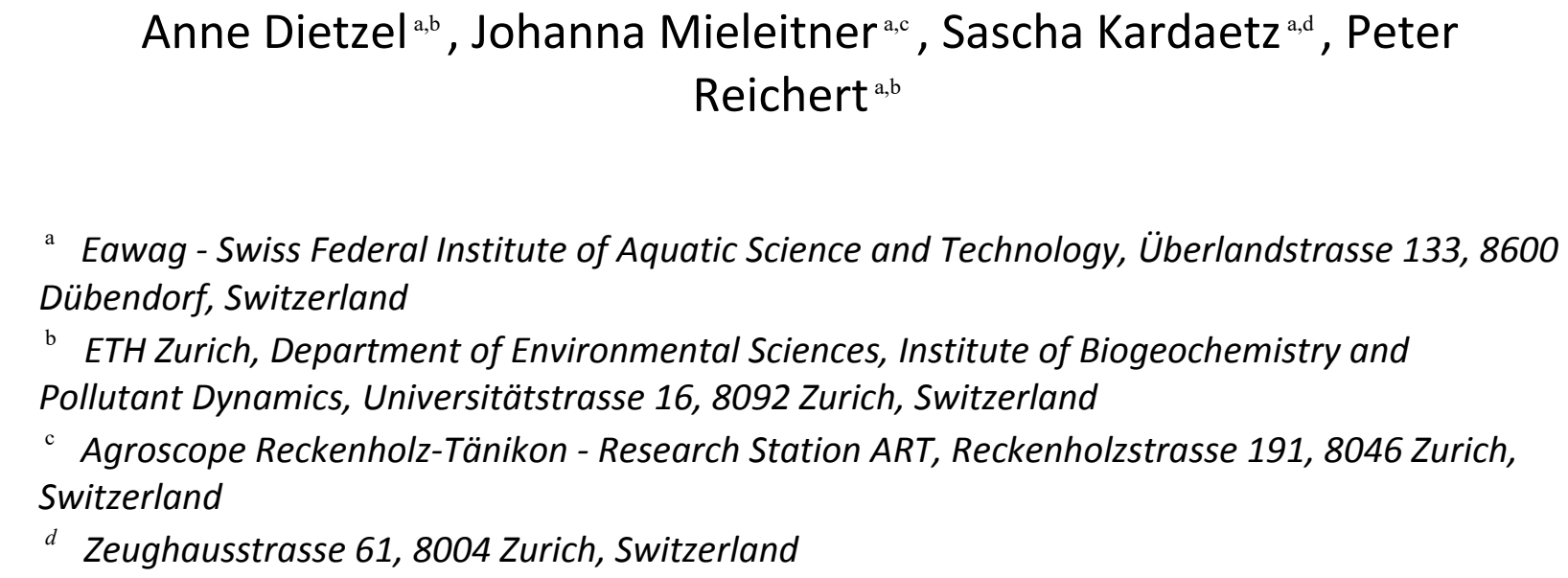

1. With a modified version of the lake model BELAMO we were able to describe the essential features of the dynamics of nutrients, dissolved oxygen, phyto- and zooplankton in three lakes of different trophic status over periods of 19 to 30 years, with essentially the same model parameters for all three lakes. This is remarkable, as the measured nutrient inputs decreased considerably during the simulated time period.

2. Despite having done this before for a period of 4 years with an earlier version of the model, a considerable effort was required that led to a series of model modifications without which the data could not be matched. This demonstrates that long-term calibration of a model that combines processes in the water column with mineralization in the sediment can be difficult.

3. Due to the necessarily simplified processes within the model, there is a bias in its output. We applied a recently developed technique for model calibration and uncertainty analysis to address bias and multiple calibration criteria. To account for the demanding long-term simulations, a simplified numerical implementation of this technique was used. 
4. Our results demonstrate good knowledge of the chemical state of the lake during the calibration period and less knowledge of the biological variables. The credibility intervals used to visualize this knowledge widen substantially during the prediction period consisting of the last 10 years of the simulation.

5. The joint calibration of the model to long-term data from lakes of different trophic status is possible but only with considerable prediction uncertainty. Due to the explicit consideration of bias in our calibration technique we are able to estimate quantitatively the uncertainty of our knowledge about chemical and biological variables in the lake.

Keywords: Lake modelling; Input loads; Long-term; Universality; Model bias. 


\section{Introduction}

Water quality and plankton dynamics are important indicators of the ecological status of a lake. In addition to a general responsibility to conserve ecosystems, deterioration in lake water quality affects human interests directly. However, water quality and plankton dynamics are affected by many factors. For example, wastewater is discharged into lakes, agriculture produces diffuse loads of herbicides and nutrients directly, and similarly polluted flow into lakes. Due to the installation and improvement of wastewater treatment plants and to changes in the use of chemicals in households and industry, in agricultural practice, in the human population and the climate, these external driving forces shift significantly over time.

To understand the behaviour of a lake under changing driving forces (such as nutrient loads or climate change), modelling is an important tool. A model used for this purpose should represent our quantitative understanding of the main biogeochemical and ecological processes within the lake and it should be as universal as possible. As stated by Mieleitner \& Reichert (2006), a high degree of universality of ecological models is important for two main reasons. First, from a fundamental research perspective, indicates that the model captures the dominant underlying mechanisms. Second, from an applied perspective, universality gives a model predictive power even when driving forces are changing. To evaluate and check the universality of biogeochemical-ecological lake models, case studies should be performed for different lakes and over time periods during which the external driving forces may shift considerably.

Several lake models have been developed and applied over the past few decades (for reviews about lake modelling see Arhonditsis \& Brett (2004), Jørgensen (2010) and Mooij et al. (2010)). These include SALMO (Benndorf \& Recknagel, 1982), its further developments SALMO-2, SALMO-1D and SALMO-HR (Baumert \& Benndorf, 2005, Petzoldt et al., 2005), (DYRESM-)CAEDYM (Hamilton \& Schladow, 1997; Schladow \& Hamilton, 1997; Romero et al., 2004; Bruce et al., 2006; Tanentzap et al., 2007; Trolle et al., 2008; Rinke et al., 2009), PROTECH (Elliott et al., 1999a, b, 2000, 2005, 2006, 2007, 2010; Reynolds et al., 2001; Elliott \& Thackeray, 2004) and BELAMO (Omlin et al., 2001a, b; Mieleitner \& Reichert, 2006, 2008). We used the 
Biogeochemical and Ecologial LAke MOdel (BELAMO) and assessed its of the universality by applying it to lakes of different trophic status over a long period. The main reason for this choice (and for the development of BELAMO) was the emphasis of the model on closing the element cycles by coupling a lake water column model with a sediment model and explicitly modelling mineralization of organic particles in the sediment rather than parameterizing only the effect of the sediment on the water column by source or sink terms of nutrients and dissolved oxygen. This was identified as a major deficit of most lake models by Mooij et al. (2010) and it is of relevance for investigations of the effect of changes in nutrient inputs.

The model BELAMO aims at a joint calculation of mass balances of nutrients, oxygen, organic particles, phytoplankton and zooplankton in the lake water column and two sediment layers. The results of applying BELAMO, originally implemented for Lake Zurich only (Omlin et al. 2001a, b), to the lakes Greifensee and Walensee indicated that it is possible to devise a more universal model applicable to three lakes that are similar in many properties, but have different trophic status (Mieleitner \& Reichert, 2006). Later, Mieleitner et al (2008) and Mieleitner \& Reichert (2008) analysed the influence of taxonomic plankton aggregation on the universality of the lake model by extending it to consider different functional groups of phytoplankton. To refrain the computational burden, the continuous vertical resolution of the original model was reduced to four mixed compartments representing the epilimnion and the hypolimnion of the lake and two sediment layers that were already considered in the one-dimensional model (Mieleitner \& Reichert, 2008). The results indicated that the universality of the relatively simple plankton sub-model was not improved by introducing functional groups, as the predictive capability was reduced. The main reason for this was that the additional state variables of the functional groups model were less constrained by mass-balance equations than the state variables of the aggregated (i.e. total phytoplankton) model (the division of phosphate conversion by phytoplankton into contributions by different functional groups is not determined by mass-balance constraints). Additionally, total biomass was not assessed more accurately by the sum of the functional groups than by the aggregated model, and the representation of the separate concentrations of the different functional groups was poor (Mieleitner \& Reichert, 2008). 
104

105

106

107

108

109

110

111

112

113

114

115

116

117

118

119

120

121

122

123

124

125

126

127

128

129

130

131

132

133

The simulations reported by Mieleitner \& Reichert (2006) and Mieleitner \& Reichert (2008) were conducted for a period of four years only, during which the driving forces did not change significantly. Longer-term simulations covering a period of change would provide a further test of the universality of the model. In the present study, therefore, we performed simulations over the last 19 or 30 years (depending on the data available for particular lakes) of Greifensee (19 years), Lake Zurich (30 years) and Walensee (30 years), to test the model for time-independency of parameters and process formulations and for predictive power under changing environmental conditions (in particular decreasing phosphate inputs).

Our focus was to find model formulations and parameter values that led to model outputs consistent with empirical data over a long period, to reduce the systematic model errors and to estimate all the remaining uncertainties in the model, including model bias. This required the development of new, computationally efficient techniques based on work on statistical bias description (Craig et al., 1996; Craig et al., 2001; Kennedy \& O`Hagan, 2001; Higdon et al., 2004; Bayarri et al., 2007). Using the calibration technique explained in detail in Dietzel \& Reichert (2012), long-term simulations were performed with the existing data. While data for the first 9 or 20 years of the simulation period were used for calibration purposes, the last 10 years of lake data served for model validation. The uncertainty estimates for the validation period assesses the predictive power of the model.

\section{Methods}

\section{Study Area}

Greifensee and Lake Zurich are both located in the north-eastern part of the Swiss plateau (Fig. 1). The area around Greifensee is mainly agricultural, while the catchment of Lake Zurich is more urban. Walensee is south-east of the other two lakes, in the foothills of the Swiss Alps. Linthkanal, the outflow of Walensee, flows into Lake Zurich. Lake Zurich is separated into two parts by a natural dam, Seedamm. As vertical profiles were taken in the lower basin, for 
modelling we therefore concentrated on lower Lake Zurich. As measured by prevailing phosphate concentrations, Greifensee is still eutrophic, Lake Zurich mesotrophic and Walensee oligotrophic.

\section{BELAMO: Model Description}

\section{Basic model version}

The first version of BELAMO was a one-dimensional (vertical) mechanistic model of the nutrient and plankton dynamics in Lake Zurich. It calculates horizontally averaged concentrations changing with the depth of the lake. The concentrations of biochemical variables and particles in the sediment, divided into two layers, are also considered. For an introduction to the model see Omlin et al. (2001b). Mieleitner \& Reichert (2006) modified the one-dimensional model and analysed its transferability to the lakes Greifensee and Walensee.

To reduce simulation time, and to be able to conduct many simulations over several years to analyse functional phytoplankton groups, the continuous vertical resolution of the model was simplified to a box approach (Mieleitner \& Reichert, 2008). To ensure the persistence of all functional groups and to represent all groups reasonably well were difficult with this model version. At the level of total biomass, the results did not appear to be significantly better than when modelling only the total phytoplankton (Mieleitner \& Reichert, 2008). As it showed a higher predictive capability in the preceding project, we elected to use the aggregated version of the model, describing the total biomass of phyto- and zooplankton. We used the box version of the model to save computational time.

The box model describes the lake as four 'boxes', each with constant volume: epilimnion, hypolimnion and two sediment boxes. In these boxes, concentrations of ammonium, nitrate, phosphate, oxygen, degradable and inert dead organic particles and (in the aggregated version) the total biomass of phytoplankton and zooplankton are calculated.

The following biogeochemical and ecological processes are considered: growth, respiration and death of phyto- and zooplankton, aerobic, anoxic and anaerobic mineralization, nitrification and phosphate uptake by sinking particles. Physical processes that are included are: 
164 inflows into epi- and hypolimnion and outflow from the epilimnion, gas exchange with the 165 atmosphere, mixing of all dissolved substances between epi- and hypolimnion (mixing 166 coefficients were estimated from temperature data), vertical migration of zooplankton in the 167 water column, sedimentation of particles, advection (if the inflow to the lake is into the 168 hypolimnion), diffusion of dissolved substances between the two sediment layers and the water in the hypolimnion, as well as accumulation of sediment and permanent burial.

Here, we concentrated on an application of one model to several lakes that cover range

171 of trophic conditions. However, the three study lakes are all pre-alpine European lakes 172 subjected to similar climatic conditions.

173 For a detailed description of the original box version of BELAMO see Mieleitner \& 174 Reichert (2008). All structural model extensions discussed in the next section are included in $175 \quad$ Figs. 2 and 3.

\section{Model extensions}

Using the model for long-term simulations required considerable adaptations to the model used by Mieleitner \& Reichert (2008). We assumed that not all phosphorus released by sloppy feeding and excretion during zooplankton growth is dissolved, but only a fraction $f_{\text {sol }}$.

182 The fraction $1-f_{\text {sol }}$ remains as organic particles.

To account for phytoplankton that grows when phosphate is limiting, we assumed the fraction of phosphorus in organic particles entering the lakes from another lake to be smaller than from rivers $\left(a_{P, \text { inflow, lake }}<a_{P, \text { inflow }}\right)$. This was used where inflowing particles had to be assessed from measurements of particulate organic phosphorus or vice versa. The fraction $a_{P, \text { inflow,lake }}$ accounts for the inflow from the upper basin of Lake Zurich at Seedamm and from Aa Uster, a river flowing from Lake Pfäffikon into Greifensee (“Aa (U.)” in Fig. 1).

\section{Initial conditions in the sediment}


194

195

196

197

198

199

200

201

202

203

204

205

206

207

208

209

210

211

212 and:

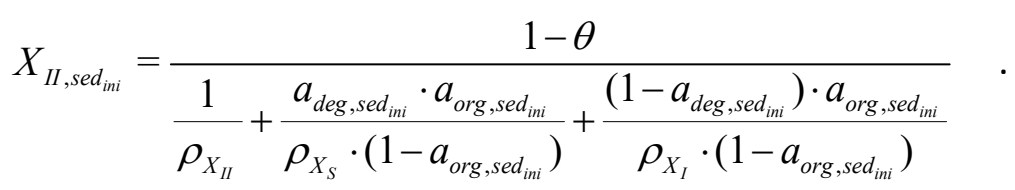

218 The parameters $a_{\text {org }, \text { sed }_{i n i}}$ and $a_{d e g, \text { sed }_{i n i}}$ re input parameters of the model and were set to 0.1 
and 0.3 , respectively. By introducing the organic fractions without phosphorus content, $X_{S}$ and $X_{I}$, it follows:

$$
X_{S}^{P}=\frac{X_{S}}{\left(1-a_{P, S}\right)}, \quad X_{I}^{P}=\frac{X_{I}}{\left(1-a_{P, I}\right)}
$$

with the phosphorus contents, $a_{P, S}$ and $a_{P, I}$, which were assumed to conform to the Redfield ratio $\left(a_{P, \text { red }}\right)$ initially (Redfield 1958). Hence, the other two initial conditions resulted in:

$$
X_{S, \text { sed }_{i n i}}=\frac{a_{\text {deg }, \text { sed }_{i n i}} \cdot a_{\text {org }, \text { sed }_{i n i}} \cdot\left(1-a_{P, \text { red }}\right)}{1-a_{\text {org }, \text { sed }_{i n i}}} \cdot X_{I I, \text { sed }_{i n i}}
$$

and:

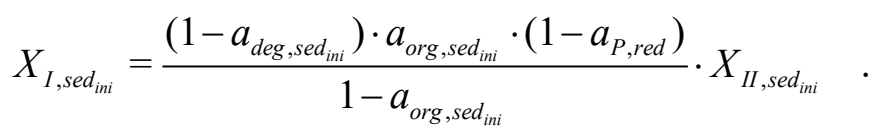

Equations (4), (6) and (7) served as initial conditions of inorganic $\left(X_{I I}\right)$, degradable organic $\left(X_{S}\right)$ and inert organic $\left(X_{I}\right)$ particles in the sediment. Note that the notation for the phosphorus mass fractions $a_{P, S}$ and $a_{P, I}$ follows the equations:

$$
a_{P, S}=\frac{X_{S}^{P}-X_{S}}{X_{S}^{P}}, \quad a_{P, I}=\frac{X_{I}^{P}-X_{I}}{X_{I}^{P}} .
$$

This notation differs from the one described in Omlin et al. (2001b) and Mieleitner \& Reichert (2006), where the mass fractions of phosphorus in organic particles were related to the organic fractions without phosphorus content. As the phosphorus content is small, this change did not have a significant effect on the model results, but is in better agreement with common notation. The calculation of phytoplankton phosphorus content was changed accordingly.

\section{Active movement of zooplankton}

In order to make the zooplankton sub-model of BELAMO more realistic, we decided not to compare with model results the volume-weighted averages of zooplankton concentration over the whole lake depth, but to use the two depth-integrated samples for an estimate of epilimnial and hypolimnial concentrations. This is described in more detail in the Supporting Information (Appendix S1) and was possible only for Lake Zurich and Walensee. With the 
244 originally zooplankton mobility component of the model, implemented in addition to normal 245 turbulent diffusion, the model tended to overestimate the zooplankton concentrations in the 246 hypolimnion and to underestimate the concentrations in the epilimnion. This was avoided by 247 switching off this active mobility component, which was originally implemented as a diffusive 248 exchange process between the two compartments, hence balancing the concentration of 249 zooplankton in the epi- and hypolimnion. The data gave hints that zooplankton moves more 250 actively towards food. Therefore, we introduced an advection process that represents the 251 movement of zooplankton to the epilimnion, where phytoplankton is present. The mass flux of 252 zooplankton from hypo- to epilimnion was formulated as follows:

$$
F_{u p, Z O O}=-v_{u p, Z O O} \cdot A_{\text {surf }} \cdot X_{\text {ZOO,hypo }}
$$

254 where $A_{\text {surf }}$ is the surface area of the specific lake and $X_{\text {ZOO,hypo }}$ is the zooplankton 255 concentration in the hypolimnion. The upwards velocity of zooplankton, $v_{u p, Z o o}$, was set to 5 $256 m d^{-1}$ of zooplankton growth by feeding on phytoplankton was modified. Zooplankton growth rate was formulated as:

$$
r_{g r o, Z O O}=k_{g r o, Z O O, T_{0}} \cdot \mathrm{e}^{\beta_{Z O O} \cdot\left(T-T_{0}\right)} \cdot \frac{S_{O_{2}}}{K_{O_{2}, Z O O}+S_{O_{2}}} \cdot f_{A L G} \cdot X_{Z O O}
$$

264 where $k_{g r o, Z o o, T_{0}}$ is the specific maximum zooplankton growth rate at the reference 265 temperature $T_{0}$ (in our case $20^{\circ} \mathrm{C}$ ), $\beta_{z O O}$ is the temperature dependence coefficient of 266 zooplankton and $T$ the actual temperature. Furthermore, the growth rate includes a 267 Monod-type limitation term for $\mathrm{O}_{2}$ ( $S$ refers to a concentration of a dissolved substance, in 268 this case measured in $\mathrm{gO} \mathrm{m}^{-3}$ ) with the half-saturation concentration for zooplankton growth 269 with respect to oxygen, $K_{O_{2}, Z O O}$, and depends on the actual zooplankton concentration, $X_{\mathrm{ZOO}}$. 270 The term $f_{A L G}$ describes the dependence of the zooplankton growth on the phytoplankton 
271 272 (2001b) and Mieleitner \& Reichert (2008), we chose the following non-linear approach:

274 with:

concentration. Rather than using a simple linear approach $f_{A L G}=X_{A L G}$, as did Omlin et al.

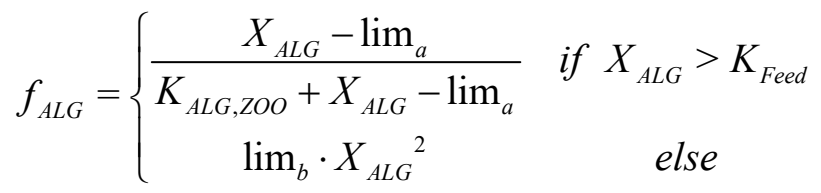

$$
\lim _{a}=\frac{K_{A L G, Z O O}+2 \cdot K_{F e e d}-\sqrt{K_{A L G, Z O O} \cdot\left(K_{A L G, Z O O}+2 \cdot K_{F e e d}\right)}}{2}
$$

and:

$$
\lim _{b}=\frac{K_{\text {Feed }}-\lim _{a}}{K_{\text {Feed }}^{2} \cdot\left(K_{A L G, Z O O}+K_{\text {Feed }}-\lim _{a}\right)}
$$

For small phytoplankton concentrations below the threshold for feeding $\left(K_{\text {Feed }}\right)$, calibrated to $0.95 \mathrm{gDM} \mathrm{m} \mathrm{m}^{-3}$ for all three lakes, the dependence on phytoplankton is quadratic; above that threshold it has a Monod-type limitation. This accounts for the assumption that zooplankton consume disproportionately less phytoplankton when food concentration is low. Test simulations showed that this modified growth rate solved the problem of very low modelled phytoplankton concentrations (in data not shown) as described by Mieleitner \& Reichert (2006) and Mieleitner \& Reichert (2008). The Monod-type limitation guarantees that zooplankton do not grow too much at high phytoplankton concentrations. For the Monod limitation, $K_{A L G, Z O O}$ is the half-saturation concentration for the growth of zooplankton on phytoplankton and was set to $0.8 \mathrm{gDM} \mathrm{m}$. The two factors, $\lim _{a}$ and $\lim _{b}$, were chosen such that $f_{A L G}$ and its derivative are continuous for every value of $X_{A L G}$. For a visualization of the function $f_{A L G}$, see Fig. S1 in the Appendix. It is apparent that the visualized response is similar to the more common ecological modelling approach of a Holling-type III functional response (Holling, 1959a; Holling, 1959b). One reason for the choice of such a functional response is the spatially heterogeneous distribution of prey, which is also the reason for the choice of the approach here. The main difference between the two approaches is that the point for switching from a quadratic to a Monod-type limitation is not fixed to half of the maximal rate, as in the Holling-type III definition. The threshold $K_{\text {Feed }}$ was calibrated to a value 
corresponding to $30 \%$ (and not $50 \%$ ) of the maximal rate in our application.

$$
\text { Feeding by Diptera }
$$

Mieleitner \& Reichert (2008) mentioned that modelled zooplankton concentrations are also often too low, especially in the Greifensee. After discussions with a plankton specialist (H.-R.Bürgi, Eawag), it was decided to change the formulation of the zooplankton death rate by introducing the predation by Diptera larvae (genus Chaoborus), most abundant in the shallow Greifensee (Mieleitner \& Reichert, 2006). To account explicitly for that, we introduced a Diptera model part by splitting the death rate of zooplankton into two processes. "Normal" mortality has the rate $r_{\text {death }, Z O O}=k_{\text {death }, Z O O, T_{0}} \cdot \mathrm{e}^{\beta_{Z O O} \cdot\left(T-T_{0}\right)} \cdot X_{Z O O}$, which is linearly dependent on the zooplankton concentration and includes predation by fish. $k_{\text {death, } Z O o, T_{0}}$ is the specific death rate and $\beta_{z o O}$ describes the temperature dependence. The specific zooplankton death rate was set to the same value for all three lakes before calibration. An additional source of mortality due to predation by Chaoborus, only active in Greifensee, was specified and implemented in a similar way as zooplankton grazing on phytoplankton described above to account for lower grazing efficiency at low concentrations. Equation (14) shows the formulation of the process rate

$$
r_{\text {death }, Z O O, \text { Dipt }}=k_{\text {death,ZOO,Dipt }, T_{0}} \cdot \mathrm{e}^{\beta_{Z O O} \cdot\left(T-T_{0}\right)} \cdot f_{\text {ZOO }} .
$$

The dependence on zooplankton, $f_{z o O}$, is described as

$$
f_{\text {ZOO }}=\left\{\begin{array}{cc}
\frac{X_{Z O O}{ }^{2}}{2 \cdot K_{\text {Feed }, Z O O, \text { Dipt }}} & \text { if } X_{\text {ZOO }}<K_{\text {Feed,ZOO,Dipt }} \\
X_{Z O O}-\frac{K_{\text {Feed }, \text { ZOO,Dipt }}}{2} & \text { else }
\end{array} .\right.
$$

316 At the threshold zooplankton concentration, $K_{\text {Feed,Zoo,Dipt }}$, predation by Chaoborus switches 317 from a quadratic to a linear dependency on zooplankton concentration, rather than switching to 318 a Monod-type limitation as for zooplankton grazing. Test simulations showed that this new 319 implementation no longer allows the concentration of zooplankton to decrease dramatically, in 320 better agreement with the data. The specific death rate due to Diptera feeding was set to 0.085 $321 \mathrm{~d}^{-1}$, and was not included in the calibration, but the parameter calibration resulted in different 
322 values of the specific zooplankton death rate, $k_{\text {death,Zoo, } T_{0}}$, for the three lakes. This could be due

323 to differences in the fish population in the three lakes and could be represented by a separated

324 fish model component.

\section{Nutrient preference of phytoplankton}

Another model change resulted in a more realistic description of the nutrient preference of phytoplankton. To ensure that phytoplankton favours ammonium over nitrate in a way that is still valid at low concentrations of both ammonium and nitrate, we used the following rate descriptions for phytoplankton growth implemented as two processes (one for growth on

332 ammonium and one for growth on nitrate):

$$
\begin{aligned}
r_{\text {gro }, A L G, N H_{4}} & =k_{\text {gro }, A L G, T_{0}, I_{0}} \cdot f_{\text {lim }, T} \cdot f_{\text {lim }, I} \cdot \operatorname{pref}_{\mathrm{NH}_{4}, \mathrm{NO}} \\
\cdot \min & \left(\frac{S_{\mathrm{NO}_{3}}+S_{\mathrm{NH}_{4}}}{K_{N, A L G}+S_{\mathrm{NO}_{3}}+S_{\mathrm{NH}_{4}}}, \frac{S_{\mathrm{HPO}_{4}}}{K_{\mathrm{HPO}_{4}, \mathrm{ZOO}}+S_{\mathrm{HPO}_{4}}}\right) \cdot X_{A L G}
\end{aligned}
$$

335 and:

$$
\cdot \min \left(\frac{S_{\mathrm{NO}_{3}}+S_{\mathrm{NH}_{4}}}{K_{\mathrm{N}, \mathrm{ALG}}+S_{\mathrm{NO}_{3}}+S_{\mathrm{NH}_{4}}}, \frac{S_{\mathrm{HPO}_{4}}}{K_{\mathrm{HPO}_{4}, \mathrm{ZOO}}+S_{\mathrm{HPO}_{4}}}\right) \cdot X_{A L G} \cdot
$$

338 The terms $f_{\lim , T}$ and $f_{\lim , I}$ account for the limitations of phytoplankton growth due to 339 temperature, $T$ and light intensity, $I$. The temperature dependence is formulated as an 340 exponential limitation, and the dependence on light intensity as a Monod-type limitation. Hence, 341 the specific growth rate, $k_{g r o, A L G, T_{0}, I_{0}}$, refers to reference temperature and saturating light 342 intensity. Furthermore, both growth processes are limited by phosphate $\left(S_{\mathrm{HPO}_{4}}\right)$ and total 343 nitrogen concentration $\left(S_{\mathrm{NO}_{3}}+S_{\mathrm{NH}_{4}}\right)$. For nutrient concentrations below their specific 344 half-saturation constant, $K_{N / P, A L G}$, the nutrient concentration at which the difference to the 345 half-saturation constant is larger, controls the limitation, following Liebig's law of the minimum.

346 The "preference factor", pref $_{\mathrm{NH}_{4}, \mathrm{NO}_{3}}$, was newly introduced into the equations as: 


$$
\operatorname{pref}_{\mathrm{NH}_{4}, \mathrm{NO}_{3}}=\frac{p_{\mathrm{NH}_{4}, \mathrm{ALG}} \cdot S_{\mathrm{NH}_{4}}}{p_{\mathrm{NH}_{4}, \mathrm{ALG}} \cdot S_{\mathrm{NH}_{4}}+S_{\mathrm{NO}_{3}}}
$$

348 where the preference coefficient, $p_{\mathrm{NH}_{4}, A L G}$, which determines the magnitude of preference for 349 ammonium over nitrate, was set to 10 . As the concentration of ammonium is much lower than 350 that of nitrate, and also because phytoplankton is more limited by phosphate than by nitrogen 351 in these lakes, this change in the growth formulation changes the model results only slightly. 352 Hence, neither is the absolute value of the parameter crucial. However, this description is also 353 valid for low nitrate concentrations.

\section{Anaerobic mineralization and methane}

In the first version of BELAMO, anaerobic mineralization of organic matter was not considered (Omlin et al., 2001b). As it seemed to be relevant, especially for the sediments of the eutrophic Greifensee, it was introduced in the subsequent study (Mieleitner \& Reichert, 2006) and also transferred to the box version of the model (Mieleitner \& Reichert, 2008). The process of anaerobic mineralization was implemented with a specific anaerobic mineralization rate, $k_{\text {miner,anae,sed } T_{0}}$, a bacterial temperature dependency, $\beta_{B A C}$, inhibition terms for nitrate and oxygen, and a dependence on the concentration of organic particles, $X_{S}$ :

$$
r_{\text {miner }, \text { anae }, \text { sed }}=k_{\text {miner }, \text { anae }, \text { sed }, T_{0}} \cdot \mathrm{e}^{\beta_{B A C} \cdot\left(T-T_{0}\right)}
$$

$$
\cdot\left(1-\frac{S_{\mathrm{NO}_{3}}}{K_{\mathrm{NO}_{3}, \text { miner }}+S_{\mathrm{NO}_{3}}}\right) \cdot\left(1-\frac{S_{\mathrm{O}_{2}}}{K_{\mathrm{O}_{2}, \text { miner }}+S_{\mathrm{O}_{2}}}\right) \cdot X_{S} .
$$

This process combines anaerobic mineralization by reduction of manganese oxide $\left(\mathrm{MnO}_{2}\right.$ to $\left.\mathrm{Mn}^{2+}\right)$, iron hydroxide $\left(\mathrm{FeOOH}\right.$ to $\left.\mathrm{Fe}^{2+}\right)$, sulphate $\left(\mathrm{SO}_{4}^{2-}\right.$ to $\left.\mathrm{HS}^{-}\right)$and methanogenesis

$368\left(\mathrm{C}_{\text {org }}\right.$ to $\left.\mathrm{CH}_{4}\right)$. It was assumed that at least one of these processes occurs in the absence of oxygen and nitrate and that there is no limitation due to a lack of reducible substances. released into the hypolimnion after anaerobic mineralization in the sediment and the

372 subsequent depletion of oxygen needed for this oxidation, was not considered. This oxidation 
373 can have a significant effect on the oxygen balance in lakes. As there are no data available for

374 any of the four reduced substances, however we cannot compare any modelled concentrations

375 with data. Furthermore, the stoichiometry of all four oxidation processes is the same with

376 respect to the amount of oxygen needed for oxidation per mole of mineralized organic carbon

377 in the corresponding reduction process. For this reason, we can describe anaerobic

378 mineralization and subsequent oxidation of the reduced compound as methanogenesis.

379 Therefore we explicitly considered the production of methane $\left(\mathrm{CH}_{4}\right)$ during anaerobic

380 mineralization and introduced oxidation of methane as a new process.

381 The process rate of re-oxidation of methane in the hypolimnion (after anaerobic 382 reduction of particulate organic carbon and diffusion of methane into the hypolimnion) is 383 described as

$$
r_{\text {oxid }, \mathrm{CH}_{4}}=k_{\text {oxid, }, \mathrm{CH}_{4}} \cdot \mathrm{S}_{\mathrm{CH}_{4}} \cdot \mathrm{S}_{\mathrm{O}_{2}}
$$

385 with an oxidation rate constant, $k_{\text {oxid, } \mathrm{CH}_{4}}$. For the oxidation of $1 \mathrm{gC} \mathrm{m}^{-3}$ methane $5.33 \mathrm{gO} \mathrm{m}^{-3}$ 386 oxygen is needed. The concentration of methane increases with a total net transformation rate 387 dependent on the actual anaerobic mineralization rate referred to equation (19). According to 388 the stoichiometry of the process of methanogenesis (Reichert \& Schuwirth, 2010), resulting 389 from Redfield composition, per $1 \mathrm{gDM} \mathrm{m^{-3 }}$ organic matter, $1 / 2 \cdot a_{C} \mathrm{gC} \mathrm{m}^{-3}$ methane is 390 produced, where $a_{C}$ is the fraction of carbon ( $a_{C}$ equals $0.358 g C g D M^{-1}$ as for Redfield 391 composition) in degradable particulate organic matter $\left(X_{S}\right)$. Diffusion of methane between all 392 boxes and gas exchange with the atmosphere are considered as well. According to Cussler 393 (2009), molecular diffusivity of methane was set to $0.000129 \mathrm{~m}^{2} d^{-1}$. By a comparison with the 394 similar diffusivity of oxygen, the methane exchange velocity was set to the same as the oxygen exchange velocity, according to Schwarzenbach et al. (2003).

Inert fraction of organic particles

Sobek et al. (2009) found that the negative correlation of organic carbon burial efficiency 400 with oxygen exposure time is stronger for lakes with significant allochthonous input, for 401 example from land erosion. It follows that the rate of permanent sedimentation of organic 
402 carbon is larger for allochthonous input than for autochthonous material. This leads to the 403 implication that allochthonous organic particles are less degradable than autochthonous ones. 404 As possible reasons, Sobek et al. (2009) implicated the greater age of allochthonous material, its 405 higher degree of degradation and transformation and its richness in molecules resistant to 406 anaerobic mineralization. These findings are supported by the fact that the phosphate 407 concentration of Walensee is decreasing in the long term, which is not true of the inflow of 408 organic particles, which are the main source of the annual phosphorus load. We concluded that 409 a large fraction of these particles are only slowly degradable, because they mainly originate 410 from allochthonous input discharged by the river Linth. Hence, the fraction of slowly degradable 411 organic particles within allochthonous input, $f_{X_{I}, \text { rivers }}$, was assumed to be large (calibration 412 resulted in a value of 0.93 ), whereas that of inputs from lakes (Lake Zurich, upper basin and Lake 413 Pfäffikon), $f_{X_{I}, \text { lake }}$, was set to 0.2 , close to the fraction of the cadavers of organisms that turns 414 into slowly degradable material in the death process, $f_{p}$, which has the value 0.1 . In the model, 415 the slowly degradable particles are assumed not to be degraded within the observed time span 416 and hence were considered as inert.

\section{Sorption of inorganic phosphorus to inert particles}

The higher inert fraction of organic particles that reaches Greifensee and Walensee could not solely explain the marked decrease in phosphate concentration in Walensee over the 422 past few decades. We assumed that inorganic phosphorus, in addition to the sorption to 423 degradable organic particles introduced by Omlin et al. (2001b) as the state variable $X_{P I, S}$, also 424 adsorbs to slowly degradable organic particles while those are settling down to the sediment. 425 Another state variable, $X_{P I, I}$, was included into the model which represents the concentration 426 of inorganic phosphorus adsorbed to organic particles that are considered as inert and 427 represented by the state variable $X_{I}$. The phosphorus uptake rate of inert organic particles 428 follows the subsequent equation:

$$
r_{\text {uptake }, X_{I}}=k_{\text {upt }, X_{I}} \cdot\left(a_{P, \max , X_{I}}-a_{P I, I}\right) \cdot \frac{S_{O_{2}}}{K_{O_{2}, a d s}+S_{O_{2}}} \cdot S_{H P O_{4}} \cdot X_{I} .
$$


In this equation, $k_{u p t, X_{I}}$ represents the phosphorus uptake rate constant of $X_{I}$. The uptake rate includes a Monod-type limitation to the concentration of oxygen, $S_{\mathrm{O}_{2}}$. It depends on the

432 concentration of inert organic particles, $X_{I}$, the concentration of dissolved phosphate, $S_{\mathrm{HPO}_{4}}$, 433 and the difference between the actual fraction of inorganic phosphorus on inert organic 434 particles, $a_{P I, I}$, and the maximal fraction, $a_{P, \max , X_{I}}$. This maximal fraction was set to $4350.001 \mathrm{gP} / \mathrm{gDM}$, three times smaller than the maximal phosphorus fraction of degradable organic particles, $a_{P, \max , X_{S}}$.

Additionally to these model extensions, we also considered the possibility of internal nutrient storage capacity of plankton as potential reason for observed lake nutrient concentrations lower than predicted by the model. We studied the Droop model (Droop, 1973) accounting for internal storages as a possible alternative to the Monod model. It was concluded 441 that the two model equations are equivalent (Burmaster, 1979) for time steps larger than several days. Hence, in the considered time steps given by the monthly averaged driving forces, these processes do not play a role and the Monod model seems to be appropriate.

Table 1 summarizes all new parameters and those that have a new meaning compared to the most recent published version of the lake model (Omlin et al., 2001b; Mieleitner \& Reichert, 2008) and their actual values. For the description of parameters that changed their values due to automatic calibration, see Table 4. For their assumed prior distributions, see Table 2. There, also the parameters of the new error model are listed.

\section{Data}

451

Monthly measured profiles of physical, chemical and biological variables for Lake Zurich and Walensee were obtained from the Water Supply Authority of Zurich (Wasserversorgung Zürich (WVZ)) from 1976 to the spring of 2006. For Greifensee, monthly to daily measurements

455 of physical, chemical and biological variables were obtained from the Aquatic Ecology Department of Eawag (Swiss Federal Institute of Aquatic Science and Technology) and the environmental agency of the canton of Zurich (Amt für Abfall, Wasser, Energie und Luft der Baudirektion des Kantons Zürich (AWEL Zürich)). For chemical and physical variables for 
459 Greifensee, data were collected from 1985-2006. Phytoplankton data of Greifensee were available from 1987-2004, while zooplankton data were available for the years 1987 to 2006 .

Information on inflows to the lakes (physical and chemical variables) and meteorological

462 data were received directly from federal (Bundesamt für Umwelt (BAFU)) and cantonal agencies

463 (Amt für Umweltschutz des Kantons St. Gallen (AFU St. Gallen) and AWEL Zürich) and from WVZ.

464 Technical reports from these institutions provided insights into sampling techniques and 465 methodological details (Gammeter et al., 1996; Gammeter et al., 1997; Gammeter \& Forster, 466 2002). A detailed description of the data availability, compilation and processing can be found in 467 Appendix S1.

A comparison of the nutrient input loads (bioavailable nitrogen and phosphorus) per lake surface area from inflowing rivers, waste water treatment plants (WWTPs) and wet deposition 470 is shown in Fig. 4. In our model formulation, bioavailable nitrogen and phosphorus represent 471 the sum of the dissolved compounds (nitrate, ammonium and phosphate, respectively) and the $472 \mathrm{~N}$ - and $\mathrm{P}$-fraction of the non-inert part (1- $f_{X_{I}, \text { rivers }}$ or 1- $\left.f_{X_{I}, \text { lake }}\right)$ of the inputs of organic material.

473 It became obvious that for all three lakes the input load of bioavailable phosphorus decreased 474 considerably during the measurement period. This is particularly true of Lake Zurich and 475 Walensee, and for the period 1976 to 1987 . This is due to the introduction of phosphate-free 476 detergents, restrictions in the use of phosphate fertilizers and the connection of more 477 households to WWTPs. The introduction of phosphate precipitation in WWTPs and the ultimate 478 prohibition of detergents containing phosphate in 1986 also resulted in a decline. Exceptions 479 were the years around 2001, when some WWTPs exported higher phosphate loads to the lakes. 480 Over the same time period the mean nitrogen load did not change significantly. A comparison of 481 the inputs to the three is broadly consistent with their trophic status. For most years, the 482 bioavailable phosphorus and nitrogen loads per surface area of Greifensee were higher than for 483 Lake Zurich and Walensee, for which the loads were similar. After the significant decrease in 484 phosphorus input into Walensee, the phosphorus load to Lake Zurich exceeded that for the 485 Walensee in most years.

\section{Sensitivity Analysis}



number of parameters is done best by an iterative procedure of sensitivity analysis, parameter estimation and identifiability analysis. A sensitivity analysis measures how strongly parameter

492 changes influence the model output. A preliminary sensitivity analysis can help to identify potential parameters that must be estimated. After estimation, identifiability analysis can be used to check for problems in producing a unique estimate. The set of parameters to be

We conducted sensitivity analyses for the model results of the three lakes separately, as well as jointly for all lakes. The analyses were done according to Brun et al. (2001) and Omlin et al. (2001a) as local sensitivity analyses using linear error propagation as a measure of the contribution of each parameter to the model output error. The overall sensitivity measure $\delta_{\theta_{j}}^{m s q r}$ is calculated as

$$
\delta_{\theta_{j}}^{m s q r}(\boldsymbol{\theta})=\sqrt{\frac{1}{n_{L}} \sum_{L}\left(\frac{\Delta \theta_{j}}{s c_{\mathbf{y}_{M}^{L}}} \cdot \frac{\partial \mathbf{y}_{M}^{L}}{\partial \theta_{j}}(\mathbf{x}, \boldsymbol{\theta})\right)^{2}}
$$

using the square root of the average of the squared derivatives of all model outputs, $\mathbf{y}_{M}^{L}$, of the layout $L$ (of length $n_{L}$ ) with respect to the parameter $\theta_{j}$ times the ratio of the uncertainty range, $\Delta \theta_{j}$, of the parameter $\theta_{j}$ and the scaling factor, $s c_{\mathbf{y}_{M}^{L}}$. The layout $L$ characterizes the model output, i.e. which output variables are considered at which point of the output dimension (e.g. time/space). In our case the layout consists of combinations of the five output variables phytoplankton, zooplankton, oxygen, nitrate and phosphate, a (monthly) date and a specification of the compartment (epilimnion or hypolimnion). The chosen layout mostly equals the description of available measurements.

For local sensitivity analyses, the results differ for each combination of parameter values, $\boldsymbol{\theta}$. We will show the results of the posterior sensitivity analysis conducted for the best parameter estimate found during model calibration in the next section. The model results for 
this point in the parameter space served as scaling factor, $s c_{\mathbf{y}_{M}^{L}}$, to get non-dimensional

517 sensitivity measures and to make the influences of parameters on different output variables 518 with different units comparable to each other. The uncertainty of the parameters was chosen 519 according to Omlin et al. (2001a) by classifying all parameters into three groups of relative uncertainty (accurately known parameters $=$ class $1=5 \%$; stoichiometric parameters $/$ specific 521 growth rates $=$ class $2=20 \%$; most kinetic/poorly known parameters $=$ class $3=50 \%$ ). We did 522 not group the parameters into those able to be fitted or not in order to compare the sensitivity 523 of all parameters. Nevertheless, this distinction influenced our choice of calibration parameters.

524 We also analysed the sensitivity of the model to the parameters $a_{P, \text { inflow,lake }}, f_{X_{I}, \text { rivers }}$ and $525 f_{X_{I}, \text { lake }}$ which are related to input fluxes, but are new or have a new meaning due to model 526 extensions. Beside those, we did not include input fluxes in the sensitivity analysis, as inflow parameters did not seem to be meaningful to calibrate.

\section{Model Calibration}

Manual calibration of simulation models by experts in the presence of bias in model outputs has often been judged superior to automatic calibration, as experts take a more "holistic" view of the quality of the fit and emphasize certain characteristic patterns rather than

534 merely minimizing the average deviation of model results from observations (Boyle et al., 2000).

535 However, for computationally demanding models with high-dimensional parameter and output 536 spaces, manual calibration is almost impossible and a more systematic procedure is required. As 537 it is difficult to formalize and automate the weighting process of multiple criteria carried out by 538 experts during manual calibration, the use of multi-objective optimization techniques has been 539 suggested to determine a Pareto-set of good solutions rather than trying to find the optimal one 540 (Gupta et al., 1998; Yapo et al,. 1998; Madsen, 2000; Madsen et al., 2002; Gupta et al., 2003; 541 Boyle et al., 2003). Reichert \& Schuwirth (2012) recently adapted a statistical bias description 542 technique (Craig et al., 1996; Craig et al., 2001; Kennedy \& O`Hagan, 2001; Higdon et al., 2004; 543 Bayarri et al., 2007) to provide a statistical basis for an estimation procedure that attempts to 544 imitate and systematize expert calibration while considering systematic model errors, a 
particularly typical phenomenon in environmental modelling. This technique is based on prior specification of the magnitude of "acceptable bias" in different model variables to take into account the expert's choice of relative importance of fit objectives. An approximation to the technique of Reichert \& Schuwirth (2012) for computationally demanding models has been developed by Dietzel \& Reichert (2012) and was applied in this paper.

This technique is based on describing system observations as the sum of the output of the deterministic model, bias (systematic errors) and observation error to account explicitly for the contribution of bias in model results:

$$
\mathbf{Y}_{M}^{L}(\mathbf{x}, \boldsymbol{\theta}, \boldsymbol{\psi}, \boldsymbol{\xi})=\mathbf{y}_{M}^{L}(\mathbf{x}, \boldsymbol{\theta})+\mathbf{B}_{M}^{L}(\mathbf{x}, \boldsymbol{\xi})+\mathbf{E}^{L}(\boldsymbol{\psi})
$$

where $\mathbf{Y}_{M}^{L}$ is the vector of random variables representing the observations as described by the model, $M$, at the layout, $L$, that defines the output variables and the time points and locations at which they are observed or evaluated. $\mathbf{Y}_{M}^{L}$ depends on the external influence factors, $\mathbf{x}$, unknown model parameters, $\boldsymbol{\theta}$, and additional parameters, $\boldsymbol{\psi}$ and $\boldsymbol{\xi}$, of the error terms. It is composed of the deterministic function $\mathbf{y}_{M}^{L}(\mathbf{x}, \boldsymbol{\theta})$, representing our knowledge of the system response (i.e. the output of our model), of the random process $\mathbf{B}_{M}^{L}(\mathbf{x}, \boldsymbol{\xi})$, expressing our knowledge of model bias depending on external inputs and additional parameters and of $\mathbf{E}^{L}(\psi)$, a vector of random variables that represents the observation error, which may also depend on additional parameters. Note that when propagating the appropriate parameter distribution (either prior or posterior, depending on which output distribution we are interested in) the representation (23) allows us to distinguish the random variables representing our knowledge of the true state of the system, $\mathbf{y}_{M}^{L}+\mathbf{B}_{M}^{L}$, from the random variable representing observations, $\mathbf{Y}_{M}^{L}$, including observation errors.

Under normality assumptions for both the bias and the observation error, and after integrating out the bias, we obtain the likelihood function:

$$
\begin{aligned}
\boldsymbol{f}_{\mathbf{Y}_{M}^{L} \mid \Theta, \Psi, \Xi}\left(\mathbf{y}^{L} \mid \boldsymbol{\theta}, \boldsymbol{\psi}, \boldsymbol{\xi}, \mathbf{x}\right)= & \frac{1}{\sqrt{2 \pi}^{n_{L}}} \frac{1}{\sqrt{\operatorname{det}\left(\Sigma_{\mathbf{E}^{L}}+\Sigma_{\mathbf{B}_{M}^{L}}\right)}} \\
& \cdot \exp \left(-\frac{1}{2}\left[\mathbf{y}^{L}-\mathbf{y}_{M}^{L}(\mathbf{x}, \boldsymbol{\theta})\right]^{\mathrm{T}}\left(\Sigma_{\mathbf{E}^{L}}+\Sigma_{\mathbf{B}_{M}^{L}}\right)^{-1}\left[\mathbf{y}^{L}-\mathbf{y}_{M}^{L}(\mathbf{x}, \boldsymbol{\theta})\right]\right),
\end{aligned}
$$


571

where $\Sigma_{\mathbf{E}^{L}}$ and $\Sigma_{\mathbf{B}_{M}^{L}}$ are the variance-covariance matrices of observation error and bias, respectively. The posterior of the parameters is then given by:

$$
\begin{aligned}
\boldsymbol{f}_{\Theta, \Psi, \Xi \mid \mathbf{Y}_{M}^{L_{L}}}\left(\boldsymbol{\theta}, \boldsymbol{\psi}, \boldsymbol{\xi} \mid \mathbf{y}^{L_{1}}, \mathbf{x}\right) \propto & \frac{\boldsymbol{f}_{\Theta, \Psi, \Xi}(\boldsymbol{\theta}, \boldsymbol{\psi}, \boldsymbol{\xi})}{\sqrt{\operatorname{det}\left(\Sigma_{\mathbf{E}^{L_{1}}}+\Sigma_{\mathbf{B}_{M}^{L_{L}}}\right)}} \\
& \cdot \exp \left(-\frac{1}{2}\left[\mathbf{y}^{L_{1}}-\mathbf{y}_{M}^{L_{1}}(\mathbf{x}, \boldsymbol{\theta})\right]^{\mathrm{T}}\left(\Sigma_{\mathbf{E}^{L_{1}}}+\Sigma_{\mathbf{B}_{M}^{L_{4}}}\right)^{-1}\left[\mathbf{y}^{L_{1}}-\mathbf{y}_{M}^{L_{1}}(\mathbf{x}, \boldsymbol{\theta})\right]\right),
\end{aligned}
$$

where $f_{\Theta, \Psi, \Xi}(\theta, \psi, \xi)$ represents the prior distribution of the parameters $\theta, \psi$ and $\xi$ (see Reichert \& Schuwirth (2012) for more details). This posterior is not much more difficult to maximize than another objective function used in other calibration techniques (there are a few additional parameters in $\Sigma_{\mathbf{B}_{u}^{L}}$ ). As described in Dietzel \& Reichert (2012), we use a Box-Cox transformation (Box \& Cox, 1964) of model results and data (with $\lambda_{1}=0.5$ and $\lambda_{2}=0$ ) to account for heteroscedasticity, we derive a normal approximation to the posterior and we use linearized error propagation for deriving the posteriors of parameters and model results.

After identifying major calibration problems by manual calibration and improving the model as described above (Model extensions) to reduce these problems, this technique was applied to solve the calibration problem and to estimate uncertainties in model output due to parameter uncertainty, structural uncertainty and observation error. The identifiability problem between deterministic model output and bias was addressed by specifying a prior with a mean of zero for the bias and a prior for its standard deviation which favours a small value. This prior was parameterized by an exponential distribution with different means for different observed substances or organisms. This formalizes the preference for a small bias, but allows different magnitudes of bias for different state variables. For the measurement error, a lognormal prior distribution for its standard deviation was chosen, representing our uncertainty about the amount of observation error in each output variable. The prior distributions of all calibrated model parameters, as well as the parameters of the error model, are summarized in Table 2. The modes of the distributions were fixed approximately at the previously assumed model parameter value. The correlation length of the bias was fixed to a little under two months. Due to the use of Box-Cox transformation, the parameters of the error model are expressed in transformed units (as shown in Table 2). The parameter $f_{X_{I}, \text { rivers }}$, referring to a fraction, was 
598 transformed by an arctan function to keep it within the interval $[0,1]$. In general, most 599 influential and least known parameters were chosen to be calibrated, while trying to keep the 600 calibration and identifiability problem as small as possible. The mixing parameters were not 601 included in the automatic calibration, because they were already manually calibrated to the aggregated values of the temperatures in epi- and hypolimnion. The respiration rate constants were not included, as it had been found previously that growth and respiration rate constants show a large collinearity and are hence non-identifiable when calibrated jointly (Omlin et al., 2001a). The very influential parameter $K_{F e e d}$ was used for calibration, whereas the parameter $K_{I, A L G}$ was excluded, because it was found to be non-identifiable in earlier studies (Mieleitner \& Reichert, 2006). Stoichiometric parameters were not included either, as it was assumed that prior knowledge was the more reliable source of information than the fit of a lake model that could lead to unrealistic values. A normal approximation to the posterior was calculated by first estimating the mean and covariance matrix by importance sampling from a uniform ball around the maximum, followed by importance sampling using the normal distribution with this mean and covariance matrix as a new sampling distribution. The mean and covariance matrix of this second importance sampling are unbiased estimates of mean and covariance matrix of the posterior and were used to characterize the approximating normal distribution. This technique has proved to be the most robust for addressing the challenging problem of approximating a potentially complex shape of the posterior by a normal distribution in Dietzel \& Reichert (2012). Parameter estimation was done for 9 years for Greifensee (1987-1995) and 20 years for Lake Zurich and Walensee (1976-1995). To assess the predictive capability of the model, simulations were done also for the following 10 years without re-calibration.

\section{Model Implementation}

As previously, the model was implemented using the computer program AQUASIM for

624 simulation and identification of aquatic systems (Reichert, 1994;

625 http://www.aquasim.eawag.ch). Initial model calibration was done manually; sensitivity 626 analyses and calibrations in later stages were performed by coupling AQUASIM to UNCSIM, a 627 tool for statistical inference and sensitivity, identifiability and uncertainty analysis with arbitrary 
628 simulation programs (Reichert, 2005). The uncertainty analysis was done by coupling AQUASIM

629 to the statistics software R (http://www.r-project.org/).

630

631

632

633

634

635

636

637

638

639

640

641

642

643

644

645

646

647

648

649

650

651

652

653

654

655

\section{Results}

\section{Sensitivity Analysis}

Table 3 shows the sensitivity ranking of all model parameters including the input parameters $a_{P, \text { inflow,lake, }} f_{X_{I}, \text { rivers }}$ and $f_{X_{I}, \text { lake }}$. It reflects, in linear approximation, the amount of influence of each parameter, $\theta_{j}$, within its uncertainty range, $\Delta \theta_{j}$, (see above Sensitivity Analysis for the choice of the uncertainty ranges of the parameters) on all the model results of the five output variables phytoplankton, zooplankton, oxygen, nitrate and phosphate in the two water compartments of the three lakes. Larger values of $\delta_{\theta_{j}}^{m s q r} \quad$ [equation (22)] indicate a larger change in the model results due to a change in the respective parameter. An explanation of the parameter names can be found in Tables 1 and 2, as well as in Omlin et al. (2001b) and Mieleitner \& Reichert (2006).

It becomes obvious that the parameters describing the mixing of the three lakes in summer and winter (for example $K_{z, \text { summer,gre }}$ and $K_{z, \text { winter }, z h}$, as well as the temperature difference at which the mixing switches from winter to summer conditions, tempdif ${ }_{g r e}$, tempdif ${ }_{z h}$ and tempdif ${ }_{\text {wal }}$ ) are very influential. This is a meaningful result as those parameters influence the distribution of the concentrations of all output variables between the two lake model compartments and the onset of stratification in spring is a very crucial determinant of the initiation of phytoplankton growth. As mentioned above, these parameters were calibrated manually to the measured temperatures. Also influential were kinetic parameters describing the growth, death and respiration of the phyto- and zooplankton. The respiration rate coefficients contributed less to model output changes than did the growth and death rates of the same plankton community. The parameters $K_{F e e d}$ and $K_{I, A L G}$ were strongly influential, as well as 
some of the stoichiometric parameters, such as the factor converting zooplankton dry mass to wet mass, $w_{Z O O}$, and the maximum phosphorus content of newly produced phytoplankton, $b_{P, \max }$. The results of the joint sensitivity analysis (Table 3) were mostly in agreement with the results of the lake-specific analyses. More information about the lake-specific sensitivity analyses can be found in Appendix S2 and Table S1.

\section{Model Calibration}

In the following, the model outputs for phyto-, zooplankton, nitrate, phosphate and oxygen are compared to data from the three lakes over the whole simulation period $(19 / 30$ years). For each output variable we chose to depict the results of the compartment that showed the strongest dynamics (hypolimnion for oxygen, epilimnion for the others). The model results are the medians of the posterior (see below a discussion of uncertainty) calculated by linearized propagation of a normal approximation to the posterior of the parameters, as summarized above in Methods and described in detail by Dietzel \& Reichert, 2012). The posterior of the parameters was calculated based on a calibration period of 9 and 20 years. In general, we tried to calibrate as few parameters as possible, to not increase the identifiability problem, but as many parameters as needed to get reasonable results. Table 4 summarizes all parameter values changed due to automatic calibration, with the best estimates of their values representing the maximum of the (non-approximated) posterior distribution. For the remaining parameter values, we refer to Omlin et al. (2001b), Mieleitner \& Reichert (2006), Mieleitner \& Reichert (2008) and Table 1. Except for the mixing coefficients, the thicknesses of the sediment boxes and sediment mineralization rate constants, as well as lake-specific zooplankton death rates and gas exchange velocities differing by wind speeds, these parameter values were kept the same for all three lakes.

Compared to Mieleitner \& Reichert (2008) some parameter values changed during calibration. The growth rate coefficient of zooplankton took a new meaning (and unit) due to the changes in model formulation (see Model extensions). For this reason, the change from 0.4 $D M^{-1} \mathrm{~m}^{3} \mathrm{~d}^{-1}$ to $1.27 \mathrm{~d}^{-1}$ only reflects the change in model structure. The specific growth rate of phytoplankton decreased slightly from $1.6 \mathrm{~d}^{-1}$ to $1.51 \mathrm{~d}^{-1}$. Except for Greifensee, the death rate 
coefficients of zooplankton decreased somewhat, while the order of magnitude stayed the same. The lowest death rate coefficient was still found for Walensee and the highest for Greifensee. This agrees with expected fish densities across the eutrophication gradient of these lakes. Mineralization rate coefficients in the sediment are parameters that can be expected to vary because they aggregate effects of bacterial density, growth rate and geometric resolution of the sediment. Except for the aerobic mineralization rate coefficient of Greifensee, all mineralization rate constants increased by 1-2 orders of magnitude. Largest increases were found for the anaerobic mineralization and for Walensee. As before, Greifensee showed the greatest mineralization rate coefficients and Walensee the smallest. This is in agreement with our perception of the bacterial abundance at the different trophic levels. Compared to the model calibration for Lake Zurich only (see Dietzel \& Reichert, 2012), the results of the calibrated parameter values showed some similarities. The parameters of the error model in particular were in good agreement with the joint calibration results. For the mineralization rates of Lake Zurich, the lake-specific calibration led to smaller values, but to the same order of magnitude and the same succession of the three mineralization processes. As those parameters are lake-specific parameters, they should result in very similar values during the different calibrations. The divergences demonstrate the difficulty and complexity of the calibration problem. During calibration of Lake Zurich only, the growth rate of phytoplankton was found to be smaller than during joint calibration of all lakes, while the zooplankton growth rate was larger. This can result from differences in the composition of plankton communities between lakes that effect growth rates. Also, the divergences can again be an indication for the complexity of the calibration problem or for an identifiability problem.

\section{Greifensee}

For a comparison of data and model results, data points (markers) only have to be compared with the dashed line during the calibration period, which becomes a bold line during validation and represents the output of the deterministic model at the maximum of the approximate posterior distribution (Fig. 5). The other lines and areas are discussed below. For a more direct comparison of data and best simulation results gained by calibration, as well as 
results for compartments not shown herein, see Fig. S2 in Appendix S3.

For most state variables the modelled concentrations were in good agreement with the measured concentrations. The long-term trends in plankton and phosphate concentrations were well represented by the model, whereas the modelled annual patterns of plankton showed a less dynamic behaviour than the measurements. Year-to-year variability of plankton was less pronounced in the calculations. Additionally, calculated zooplankton concentrations were still too low, as well as phosphate concentrations in some years. Nitrate and oxygen concentrations in the compartment shown tended to be too high; the model was not always able to show the anoxic conditions in summer.

\section{Lake Zurich}

Even better results are found for the mesotrophic Lake Zurich (Fig. 6). The long-term trends of plankton, nutrients and oxygen were well represented by the model. Best results were achieved for oxygen and phosphate. For the latter, the model results captured the decreasing long-term trend very well. Nitrate matched the data less well, as the model indicated higher concentrations and less annual dynamics in the epilimnion than the measurements. More results for Lake Zurich can be found in Fig. S3 in Appendix S3.

\section{Walensee}

In the progress of calibration, the results for Walensee showed the greatest discrepancies with the data. This was especially true for phosphate concentration that did not represent the significant decline apparent in the data. Introducing the additional sorption process, which decreased the actual phosphate load, reduced the problem. After intensive calibration studies, the calculations agreed with the data about as well as for the other lakes (Fig. 7). In general, the model captured the measured long-term trends. However, in Walensee the oxygen concentration in the hypolimnion also tended to be too high. Modelled nitrate concentrations showed similar problems as for Lake Zurich, concentrations were too high and not so dynamic as the data. Phosphate concentration showed the decreasing trend over time, 
746 but the decline was rather too rapid in the first years. See Fig. S4 in Appendix S3 for a 747 comparison of epilimnion and hypolimnion results of Walensee.

\section{All Lakes}

750

In general, most output variables showed a good agreement with the measured concentrations. The long-term trends, where present, of all output variables were reproduced well by the model. This was especially obvious in the temporal changes in phosphate and plankton, in particular for Lake Zurich and Walensee. Recurring problems for all three lakes included annual dynamics of some of the output variables that were too smooth or even out-of-phase, as for the zooplankton in the hypolimnion of Lake Zurich (Appendix S3). Furthermore, concentrations of nitrogen and oxygen were too high and plankton too low (especially zooplankton). These are persistent problems while applying BELAMO. Overall, the results indicate only a coarse representation of the plankton dynamics in these lakes but a more detailed representation of the biogeochemistry.

\section{Uncertainty Analysis}

763

The dark shaded areas in the plots shown in Figs. 5-7 represent the 95\% credibility intervals of our posterior knowledge of the true states (marginal posterior distributions of the components of $\mathbf{y}_{M}^{L}+\mathbf{B}_{M}^{L}$ in equation (23)) of the variables shown in the different plots. The light shaded extensions of these areas represent our uncertainty about new observations (including observation error).

The results demonstrate that our knowledge of the true state was much more accurate 770 during the calibration period (up to 1995) than during the prediction period (after 1995) (Figs. 771 5-7). This follows from the information about the bias gained during the calibration period due 772 to comparison with data. For the prediction period, we lost information about the direction and 773 the absolute amount of bias at each time point, but we kept knowledge about the uncertainty 774 due to bias. This led to larger credibility intervals and to merged results of the deterministic model and the median of the posterior of model results plus bias during the prediction period. 
776 The model was significantly more accurate for the chemical variables than for phyto- and 777 zooplankton. A comparison of the light shaded extensions with the dark shaded areas indicates 778 that the observation error can be neglected compared to the bias for all chemical variables, 779 whereas it led to increased uncertainty for observations of phyto- and zooplankton.

As the objective of this study was a joint calibration of the same model to all investigated lakes, the same parameters for the bias were applied to all lakes. This implies that the bias considers not only bias within the time series of a single lake, but also across lakes.

\section{Nutrient Mass Fluxes}

Nutrient fluxes for the three lakes were calculated with the calibrated version of BELAMO and encompass the dissolved nutrients as well as their fractions in degradable organic material (Figs. 8 \& 9). Within the model, the bioavailable parts of the nutrients were represented by the state variables of their dissolved compounds $\left(\mathrm{S}_{\mathrm{HPO}_{4}} ; \mathrm{S}_{\mathrm{NO}_{3}}+\mathrm{S}_{\mathrm{NH}_{4}}\right)$ and their

790 fractions in degradable organic material $X_{P, S}$ (the variable fraction of phosphorus within 791 degradable organic particles $X_{S}$ ), $X_{P I, S}$ (see Model extensions), $X_{P, A L G}$ (the variable 792 fraction of phosphorus in phytoplankton $X_{A L G}$ ), the constant fraction of phosphorus in $X_{Z O O}$ 793 and the constant fractions of nitrogen in $X_{A L G}, X_{Z O O}$ and $X_{S}$ ). Figs. 8 \& 9 depict the main 794 transfer processes as input, output, sedimentation, mineralization and subsequent release of 795 the dissolved compounds to the water phase, diffusion between water and sediment and denitrification in case of nitrogen. The accumulation in the water phase shows the calculated accumulation in the model. It did not completely match the difference between input and output fluxes in all cases. Those errors are below $5 \%$ and within the range of numerical inaccuracies due to non-continuous model outputs used for the calculation of fluxes. Fig. 8 800 visualizes the importance of denitrification that increases with increasing nutrient richness. For 801 oligotrophic Walensee only slightly more than $10 \%$ of the nitrogen input was denitrified, for mesotrophic Lake Zurich this fraction amounted to around 35\% and for eutrophic Greifensee to even more than $55 \%$. 


\section{Discussion}

806

We discuss two major aspects of this study. In the first section, we discuss what we have learned about causes, reduction and dealing with remaining systematic errors. In the second, we elaborate on relevant ecological processes in the studied lakes.

\section{Bias}

As systematic errors are the main concern in any predictive modelling, we discuss the following three aspects of systematic errors in the following section: causes of bias, reduction of bias, and consideration of bias for model calibration and prediction. We then discuss biogeochemical implications and findings resulting from the model presented.

\section{Causes of Bias}

Systematic deviations of model outputs from observations are primarily caused by the simplified description of reality by the model. Main problems are neglected or unknown external influence factors and the use of a simplified model structure, including potential simplifications by aggregation (in time, space or state variables; by the model or by sampling procedures) and by the choice and parameterization of processes considered in the model.

A first major problem in our current simulations was spatial aggregation. For computational reasons, the model divides the lake water column into two mixed boxes (with constant volumes) only, the epilimnion and the hypolimnion. This leads to a poorer representation of vertical mixing processes than in the $1 \mathrm{~d}$ model used earlier for shorter simulation periods (Omlin et al., 2001b; Mieleitner \& Reichert, 2006) and it neglects variations in mixing depth. In addition, both model versions neglect horizontal inhomogeneity. This problem becomes even worse, as the depth-integrated samples of zooplankton (and phytoplankton, in case of Greifensee) do not fit directly to the resolution of compartments in the lake model. Hence, the aggregated and processed data might not represent the average 
834 concentrations in epi- and hypolimnion as described by the model compartments. The amount 835 of bias in these cases supports the finding. The problems caused by the high spatial aggregation, 836 might be solved by simulations with the one-dimensional model version and comparison with 837 concentration profiles where possible.

A second problem was the aggregation of more than 100 species to only single groups of 839 phytoplankton and zooplankton. On the one hand, this may simplify the description of nutrient 840 fluxes (see Mieleitner \& Reichert (2008) for a discussion of potential problems), but on the 841 other hand it makes it necessary to use average kinetic characteristics and behaviours for the 842 whole group. This does not account for the variability in species attributes and composition of 843 the ecological community, and in particular not for the succession of dominant species within 844 each year. Least of all, genetic adaptation or acclimatization processes of the plankton 845 community are considered, except for changes in phosphorus content.

A further important potential source of bias was our attempt to fit jointly three lakes of 847 different trophic status with a single model and with a minimum of lake-specific parameters 848 over a long simulation period during which the phosphorus input changed considerably. This 849 requires a model structure and parameterization that is considerably more universal than for 850 describing a single lake over a shorter period. In particular, the addition of potential bias across 851 lakes to the bias within time series of each lake obviously increases the bias. Our task of jointly 852 modelling all lakes over such a long period of time obviously challenges the model and it is a 853 significant result of our study to demonstrate that this is possible.

Another challenge was the use of a model with closed mass balances that describes mineralization of sedimented organic particles rather than using sediment oxygen demand and ammonia and phosphate release as external parameters, as is still done in the majority of 857 models (Mooij et al., 2010). In addition to limiting the degrees of freedom of exchange 858 processes, this required a mineralization model for the sediment. As the different mineralization processes were described by just a single overall lake-specific mineralization rate, the microbial community was (implicitly) assumed to be constant. For example, the problems in representing 861 the anoxia in Greifensee in some years could result from difficulties in finding adequate mineralization rates for the whole simulation time due to changes in the bacterial community 863 which the model does not describe. The dynamics of microbial communities, changes in 
864 bacterial abundance and adaptation processes to nutrient loads and availability of organic 865 material, were not explicitly taken into account. The introduction of biomass of mineralizing 866 bacteria as an additional state variable would be a meaningful extension to tackle this problem.

867 But one has to be aware that this would also cause additional difficulties, as it increases the 868 complexity of the model. The increased number of parameters would also increase the calibration problem, especially because the number of model output variables that can be fitted to data cannot be increased, as there are no bacteria data available.

\section{Reduction of Bias}

Although the model used in previous studies led to good simulations of all three lakes over a period of four years without significant changes in input, the model required important changes in order to be able to describe correctly the observed trends in phosphate and plankton concentrations, while still being able to represent correctly nitrate and dissolved oxygen concentration. The most important changes were (see Model extensions for more details):

- introduction of active movement of zooplankton to the epilimnion;

- improvement of the formulation of zooplankton growth to decrease the growth rate for small phytoplankton concentrations more strongly than linearly;

- improvement of the formulation of predation on zooplankton by Chaoborus similarly to zooplankton growth on phytoplankton;

- improvement of the dissolved oxygen mass balance of anaerobic mineralization by introducing methane production and subsequent re-oxidation in the water column (this process also represents the effect of mineralization by sulphate, iron oxide and manganese oxide reduction and subsequent re-oxidation);

- reduction of the biodegradability of organic particles in the inflow to decrease their release of phosphate into the lake;

- addition of sorption of phosphate to sedimenting "inert" organic particles additionally to

892 These modifications led to a considerable reduction in bias and a reasonable representation of

893 key features of the data. Nevertheless, significant discrepancies between model results and 
data remained. These discrepancies were larger and more systematic than expected for observational errors and must be considered during the model calibration process to make it possible to get adequate uncertainty estimates of model parameters and predictions.

\section{Consideration/Description of Bias}

The chosen calibration method used a bias description approach that was originally published in the statistical literature (Craig et al, 1996; Craig et al., 2001; Kennedy \& O`Hagan, 2001; Higdon et al., 2004; Bayarri et al., 2007), subsequently transferred to environmental applications and linked to multi-objective model calibration (Reichert \& Schuwirth, 2012), and finally approximated to make it applicable for computationally demanding models (Dietzel \& Reichert, 2012). Application of this technique to our long-term lake simulations led to the consideration of important aspects that are not yet commonly addressed in environmental modelling:

- Separation of bias and observation error: While the bias component shows autocorrelated behaviour characteristic of structural errors, the observation error is approximately independently and normally distributed (in our application on a Box-Cox transformed scale, see Model Calibration in Methods).

- Consideration of bias in uncertainty estimates of model parameters: The description of the bias as an autocorrelated process (partially) solves the problem that the uncertainty of model parameters is underestimated with an independent error model that does not account for bias.

- Consideration of bias for model predictions: The chosen technique allowed us to predict the current state of knowledge of the true model variables as well as about (future) observations. It naturally leads to narrow prediction credibility intervals during the calibration period, where the observations constrain the model output, and to (much) wider intervals during the prediction period. This is an important aspect that is not included in most calibration techniques currently applied in environmental modelling. However, consideration of bias for predictions is based on the assumption that model and bias structure do not change. This is obviously a strong assumption that can hardly be avoided for the bias component, as it describes the deviations that cannot easily be 
described by a mechanistic model.

- Bias of a joint simulation: In our application, systematic errors were even increased by the objective of jointly describing three lakes of different trophic status and varying input loads over a long time period. This requires a very high degree of universality of the model. Such a high degree of universality is a desired property of a model as it increases our confidence of model predictions under changes in driving forces; but it makes calibration even more challenging.

\section{Biogeochemical and Ecological Processes}

This project with the lake model BELAMO provided some insights into the biogeochemistry and ecology of the Swiss lakes Greifensee, Lake Zurich and Walensee. The comparison of model results with measurements indicated a more complex than linear dependence of zooplankton grazing on phytoplankton concentration when phytoplankton concentrations are low. This functional description has similarities to a Holling-type III response (Holling, 1959a; Holling, 1959b). The heterogeneity of plankton abundance is a possible explanation for that. Furthermore, the upwards movement of zooplankton seems to be an important process impacting the grazing of zooplankton on phytoplankton and the distribution of zooplankton between epi- and hypolimnion. A comparison of the three lakes indicates the influence of insect larvae on zooplankton concentration in Greifensee, not present in Lake Zurich and Walensee. Additionally, the different calibration results (see Table 4 for calibrated parameter values) for the death rates of zooplankton in the three lakes give evidence for an increasing predation pressure by fish on zooplankton with increasing nutrient richness across the trophic gradient. The trophic status of the lakes is also the reason for the different importance of the three mineralization processes. When comparing the lake-specific sensitivity analyses (see results of lake-specific sensitivity analyses, Appendix S2), it becomes obvious that, for Walensee, aerobic mineralization is the dominant mineralization process. For Lake Zurich, the importance of anoxic mineralization is greater than in Walensee, whereas for Greifensee anaerobic mineralization also has an increased influence. These findings are supported by the calculated nitrogen mass balances, which indicated that the fraction of denitrification was 
largest for eutrophic Greifensee and smallest for oligotrophic Walensee.

Moreover, the model study supports the assumptions that allochthonous organic particles are less degradable than autochthonous and that the sorption of inorganic phosphorus to slowly degrading organic particles can be an important loss process for nutrients.

In conclusion, despite the large simplifications in system description, BELAMO represented the main aspects of the biogeochemistry and, rather more coarsely, the ecological dynamics of plankton in the study lakes. With that we are able to apply the model also to other lakes with similar characteristics as the application cases shown herein. Further work could concentrate on comparing different models applied to the same lakes as well as the same model applied to an extended range of lakes, including lakes from other climate zones. This would be possible by changing the mixing parameters in the model, according to climate. In case that the climate is not expected to change significantly in the future, predictions about the future state of a lake can also be performed. To model the effects of climate change, BELAMO would have to be coupled to a hydrodynamic model.

\section{Acknowledgments}

We thank Richard Forster (WVZ), Hans-Rudolf Bürgi (Eawag), Barbara Känel, Pius Niederhauser, Irene Purtschert and Peter Spohn from AWEL, Margot Blaser and Markus Faden from AFU St. Gallen and Daniel Streit and the department for water from BAFU for kindly providing their data on chemistry, biology and physics of the lakes, WWTPs and inflowing rivers. Karsten Rinke, Sebastian Sobek and Bernhard Wehrli are acknowledged for helpful comments on different aspects of the lake model and Rosi Siber for GIS support and the preparation of Fig. 1. We thank the Polyfaktor Designbüro (www.polyfaktor.com) for the layout of Figs. $2,3,8 \& 9$. The Swiss National Science Foundation (SNSF) is acknowledged for the financial support of the project. 


\section{References}

984

985

986

987

988

989

990

991

992

993

994

995

996

997

998

999

1000

1001

1002

1003

1004

1005

1006

1007

1008

1009

1010

1011

Arhonditsis G.B. \& Brett M.T. (2004). Evaluation of the current state of mechanistic aquatic biogeochemical modeling. Marine Ecology Progress Series, 271, 13-26.

Baumert H.Z. \& Benndorf J. (2005). Einführung in das GETAS-Projekt. Wasserwirtschaft, 95, 10-12.

Bayarri M.J., Berger J.O., Paulo R., Sacks J., Cafeo J.A., Cavendish J., Lin C.-H. \& Tu J. (2007). A framework for validation of computer models. Technometrics, 49 (2), 138-154.

Benndorf J. \& Recknagel F. (1982). Problems of application of the ecological model SALMO to lakes and reservoirs having various trophic states. Ecological Modelling, 17, 129-145.

Box G.E.P. \& Cox O.R. (1964). An analysis of transformation. J. R. Statist. Soc. B: Statistical Methodology, 26 (2), 211-252.

Boyle D.P., Gupta H.V. \& Sorooshian S. (2000). Toward improved calibration of hydrologic models: Combining the strengths of manual and automatic methods. Water Resources Research, 36 (12), 3663-3674.

Boyle D.P., Gupta H.V. \& Sorooshian S. (2003). Multicriteria calibration of hydrologic models. In: Duan Q., Gupta H.V., Sorooshian S., Rousseau A.N. \& Turcotte R. (Eds.), Calibration of Watershed Models, pp. 185-196. Washington, DC: American Geophysical Union.

Bruce L.C., Hamilton D., Imberger J., Gal G., Gophen M., Zohary T. \& Hambright K.D. (2006). A numerical simulation of the role of zooplankton in C, N and P cycling in Lake Kinneret, Israel. Ecological Modelling, 193, 412-436.

Brun R., Reichert P. \& Künsch H.-R. (2001). Practical identifiability analysis of large environmental simulation models. Water Resources Research, 37 (4), 1015-1030.

Bürgi H.-R. (1994). Seeplankton und Seesanierung in der Schweiz. Limnological Reports Danube 1994, EAWAG, Dübendorf, Switzerland and IAD, Vienna, Austria. In German.

Burmaster D.E. (1979). The continuous culture of phytoplankton: Mathematical equivalence among three steady-state models. The American Naturalist, 113 (1), 123-134.

Craig P.S., Goldstein M., Rougier J.C. \& Seheult A.H. (2001). Bayesian forecasting for 
complex systems using computer simulators. Journal of the American Statistical Association, 96, 717-729.

Craig P.S., Goldstein M., Seheult A.H. \& Smith J.A. (1996). Bayes linear strategies for matching hydrocarbon reservoir history. In: Bernardo J.M., Berger J.O. \& Dawid A.P. (Eds.), Bayesian Statistics, 5, pp. 69-95. Oxford: Clarendon Press.

Cussler E.L. (2009). Diffusion: mass transfer in fluid systems (third ed.). Cambridge: Cambridge University Press.

Dietzel A. \& Reichert P. (2012). Calibration of computationally demanding and structurally uncertain models with an application to a lake water quality model. Environmental Modelling \& Software, 38, 129-146, doi:10.1016/j.envsoft.2012.05.007.

Droop M.R. (1973). Some thoughts of nutrient limitation in algae. J. Phycol., 9, 264-272.

Elliott J.A., Irish A.E. \& Reynolds C.S. (2010). Modelling phytoplankton dynamics in fresh waters: affirmation of the PROTECH approach to simulation. Freshwater Reviews, 3, 75-96.

Elliott J.A., Irish A.E., Reynolds C.S. \& Tett P. (1999). Sensitivity analysis of PROTECH, a new approach in phytoplankton modelling. Hydrobiologia, 414, 45-51.

Elliott J.A., Jones I.D. \& Thackeray S.J. (2006). Testing the sensitivity of phytoplankton communities to changes in water temperature and nutrient load, in a temperate lake. Hydrobiologia, 559, 401-411.

Elliott J.A., Persson I., Thackeray S.J. \& Blenckner T. (2007). Phytoplankton modelling of Lake Erken, Sweden by linking the models PROBE and PROTECH. Ecological Modelling, 202, 421-426.

Elliott J.A., Reynolds C.S., Irish A.E. \& Tett P. (1999). Exploring the potential of the PROTECH model to investigate phytoplankton community theory. Hydrobiologia, 414, 37-43.

Elliott J.A., Reynolds C.S., Irish A.E. \& Tett P. (2000). Modelling freshwater phytoplankton communities: an exercise in validation. Ecological Modelling, 128, 19-26.

Elliott J.A. \& Thackeray S.J. (2004). The simulation of phytoplankton in shallow and deep lakes using PROTECH. Ecological Modelling, 178, 357-369.

Elliott J.A., Thackeray S.J., Huntingford C. \& Jones R.G. (2005). Combining a regional climate model with a phytoplankton community model to predict future changes in phytoplankton in lakes. Freshwater Biology, 50, 1404-1411. 
1042

1043

1044

1045

1046

1047

1048

1049

1050

1051

1052

1053

1054

1055

1056

1057

1058

1059

1060

1061

1062

1063

1064

1065

1066

1067

1068

1069

1070

1071

Gammeter S. \& Forster R. (2002). Langzeitunterschungen im Zürichobersee 1972 - 2000.

Technical report, Wasserversorgung Zürich, Qualitätsüberwachung.

Gammeter S., Forster R. \& Zimmerman U. (1996). Limnologische Untersuchung des

Walensees 1972-1995. Technical report, Wasserversorgung Zürich, Qualitätsüberwachung.

Gammeter S., Forster R. \& Zimmerman U. (1997). Limnologische Untersuchung des

Zürichsees 1972-1996. Technical report, Wasserversorgung Zürich, Qualitätsüberwachung.

Gupta H.V., Bastidas L.A., Vrugt J.A. \& Sorooshian S. (2003). Multiple criteria global optimization for watershed model calibration. In: Duan Q., Gupta H. V., Sorooshian S., Rousseau A.N. \& Turcotte R. (Eds.), Calibration of Watershed Models, pp. 125-132. Washington, DC: American Geophysical Union.

Gupta H.V., Sorooshian S. \& Yapo P.O. (1998). Toward improved calibration of hydrologic models: Multiple and noncommensurable measures of information. Water Resources Research, 34 (4), 751-763.

Hamilton D.P. \& Schladow S.G. (1997). Prediction of water quality in lakes and reservoirs. Part i - Model description. Ecological Modelling, 96, 91-110.

Higdon D., Kennedy M., Cavendish J.C., Cafeo J.A. \& Ryne R.D. (2004). Combining field data and computer simulations for calibration and prediction. SIAM Journal on Scientific Computing, 26 (2), 448-466.

Holling C.S. (1959). The Components of Predation as Revealed by a Study of Small-Mammal Predation of the European Pine Sawfly. The Canadian Entomologist, 91 (5), 293-320.

Holling C.S. (1959). Some Characteristics of Simple Types of Predation and Parasitism. The Canadian Entomologist, 91 (7), 385-398.

Jørgensen S.E. (2010). A review of recent developments in lake modelling. Ecological Modelling, 221, 689-692.

Jørgensen S.E., Nielsen S.N. \& Jørgensen L. (1991). Handbook of Ecological Parameters and Ecotoxicology. Elsevier.

Kennedy M.C. \& O'Hagan A. (2001). Bayesian calibration of computer models. J. R. Statist.

Soc. B: Statistical Methodology, 63 (3), 425-464.

Madsen H. (2000). Automatic calibration of a conceptual rainfall-runoff model using multiple objectives. Journal of Hydrology, 235, 276-288. 
Madsen H., Wilson G. \& Ammentorp H.C. (2002). Comparison of different automated strategies for calibration of rainfall-runoff models. Journal of Hydrology, 261, 48-59.

Mieleitner J., Borsuk M., Bürgi H.-R. \& Reichert P. (2008). Identifying functional groups of phytoplankton using data from three lakes of different trophic state. Aquatic Sciences, 70, 30-46.

Mieleitner J. \& Reichert P. (2006). Analysis of the transferability of a biogeochemical lake model to lakes of different trophic state. Ecological Modelling, 194, 49-61.

Mieleitner J. \& Reichert P. (2008). Modelling functional groups of phytoplankton in three lakes of different trophic state. Ecological Modelling, 211, 279-291.

Mooij W.M., Trolle D., Jeppesen E., Arhonditsis G.B., Belolipetsky P.V., Chitamwebwa D.B.R., Degermendzhy A.G., DeAngelis D.L., De Senerpont Domis L.N., Downing A.S., Elliott J.A., Ruberto Fragoso Jr. C., Gaedke U., Genova S.N., Gulati R.D., Håkanson L., Hamilton D.P., Hipsey M.R., 't Hoen J., Hülsmann S., Los F.H., Makler-Pick V., Petzoldt T., Prokopkin I.G., Rinke K., Schep S.A., Tominaga K., Van Dam A.A., Van Nes E.H., Wells S.A. \& J.H. Janse (2010). Challenges and opportunities for integrating lake ecosystem modelling approaches. Aquatic Ecology, 44, 633-667.

Omlin M., Brun P. \& Reichert P. (2001a). Biogeochemical model of Lake Zürich: Sensitivity, identifiability and uncertainty analysis. Ecological Modelling, 141, 105-123.

Omlin M., Reichert P. \& Forster R. (2001b). Biogeochemical model of Lake Zürich: Model equations and results. Ecological Modelling, 141, 77-103.

Petzoldt T., Rolinski S., Rinke K., König M., Baumert H.Z. \& Benndorf J. (2005). SALMO: Die ökologische Komponente des gekoppelten Modells. Wasserwirtschaft, 95, 28-33.

Redfield A.C. (1958). The biological control of chemical factors in the environment. American Scientist, 46, 205-222.

Reichert P. (1994). AQUASIM - A tool for simulation and data analysis of aquatic systems. Water Science \& Technology, 30 (2), 21-30.

Reichert P. (2005). UNCSIM - a computer programme for statistical inference and sensitivity, identifiability, and uncertainty analysis. In: Proceedings of the 2005 European Simulation and Modelling Conference (ESM 2005), Oct. 24-26, Porto, Portugal, pp. 51-55. EUROSIS-ETI. Reichert P. \& Schuwirth N. (2010). A generic framework for deriving process stoichiometry in 
environmental models. Environmental Modelling \& Software, 25 (10), 1241-1251.

Reichert P. \& Schuwirth N. (2012). Linking statistical description of bias to multi-objective model calibration. Water Resources Research, 48, doi:10.1029/2011WR011391.

Reynolds C.S., Irish A.E. \& Elliott J.A. (2001). The ecological basis for simulating phytoplankton responses to environmental change (PROTECH). Ecological Modelling, 140, 271-291.

Rinke K., Eder M., Peeters F., Kümmerlin R., Gal G. \& Rothaupt K.-O. (2009). Simulating phytoplankton community dynamics in Lake Constance with a coupled hydrodynamic-ecological model. Verhandlungen der Internationalen Vereinigung für theoretische und angewandte Limnologie, 30 (5), 701-704.

Romero J.R., Antenucci J.P. \& Imberger J. (2004). One- and three-dimensional biogeochemical simulations of two differing reservoirs. Ecological Modelling, 174, 143-160.

Schladow S.G. \& Hamilton D.P. (1997). Prediction of water quality in lakes and reservoirs. Part ii - Model calibration, sensitivity analysis and application. Ecological Modelling, 96, 111-123.

Schwarzenbach R.P., Gschwend P.M. \& Imboden D.M. (2003). Environmental Organic Chemistry (second ed.). New York: John Wiley.

Sobek S., Durisch-Kaiser E., Zurbrügg R., Wongfun N., Wessels M., Pasche N. \& Wehrli B. (2009). Organic carbon burial efficiency in lake sediments controlled with oxygen exposure time and sediment source. Limnology \& Oceanography, 6 (54), 2243-2254.

Tanentzap A.J., Hamilton D.P. \& Yan N.D. (2007). Calibrating the Dynamic Reservoir Simulation Model (DYRESM) and filling required data gaps for one-dimensional thermal profile predictions in a boreal lake. Limnology \& Oceanography: Methods, 5, 484-494. Trolle D., Skovgaard H. \& Jeppesen E. (2008). The Water Framework Directive: Setting the phosphorus loading target for a deep lake in Denmark using the 1D lake ecosystem model DYRESM-CAEDYM. Ecological Modelling, 219, 138-152.

Yapo P.O., Gupta H.V. \& Sorooshian S. (1998). Multi-objective global optimization for hydrologic models. Journal of Hydrology, 204, 83-97. 


\section{The Supporting Information to this manuscript contain:}

1133 Fig. S1. The dependency of zooplankton grazing on phytoplankton concentration according to 1134 equation (11).

1135 Appendix S1. Data compilation and processing.

1136 Appendix S2. Lake-specific sensitivity analysis.

1137 Table S1. Results of the lake-specific sensitivity analyses.

1138 Appendix S3: Results - Model calibration.

1139 Fig. S2. Simulation results for Greifensee for the years 1987-2005.

$1140 \quad$ Fig. S3. Simulation results for Lake Zurich for the years 1976-2005.

1141 Fig. S4. Simulation results for Walensee for the years 1976-2005. 


\section{Tables}

Table 1: Parameters that were newly introduced into the model or have different values compared to the most recently published version of BELAMO (in alphabetical order). Lake-specific parameters adjusted to temperature measurements (WVZ, AWEL Zürich) are indicated by "*".

\begin{tabular}{|c|c|c|}
\hline Name (Unit) & Value & Description \\
\hline$a_{P, \text { inflow, lake }}$ & 0.0056 & $\begin{array}{l}\text { Mass fraction of phosphorus in organic material from lakes; } \\
<\text { Redfield, accounting for phosphate limitation of phytopl. in lakes }\end{array}$ \\
\hline$a_{P, \max , X_{I}}$ & 0.001 & $\begin{array}{l}\text { Maximum mass fraction of phosphate adsorbed to inert organic } \\
\text { material }\end{array}$ \\
\hline$a_{P, \max , X_{S}}$ & 0.004 & $\begin{array}{l}\text { Maximum mass fraction of phosphate adsorbed to degradable } \\
\text { organic material }\end{array}$ \\
\hline$b_{P, \min }$ & 0.0025 & Minimum phosphorus content of newly produced phytoplankton \\
\hline$D_{C H_{4}}\left(\mathrm{~m}^{2} \mathrm{~d}^{-1}\right)$ & 0.000129 & Molecular diffusivity of methane \\
\hline$f_{\text {sol }}$ & 0.5 & Dissolved fraction of phosphorus from excretion and sloppy feeding \\
\hline$f_{X_{I}, \text { lake }}$ & 0.2 & Inert fraction of autochthonous organic particles \\
\hline$h_{\text {epi }}(\mathrm{m})(\mathrm{gre} / \mathrm{wal} / \mathrm{zh})$ & $5 / 10 / 10$ & Thickness of epilimnion (hypolimnion changed accordingly) \\
\hline$K_{A L G, Z O O}\left(\mathrm{gDM} \mathrm{m}^{-3}\right)$ & 0.8 & $\begin{array}{l}\text { Half-saturation phytoplankton concentration for zooplankton } \\
\text { growth }\end{array}$ \\
\hline$K_{\text {Feed }}\left(\mathrm{gDM} \mathrm{m}^{-3}\right)$ & 0.97 & $\begin{array}{l}\text { Threshold phytoplankton concentration when zooplankton feeding } \\
\text { switches to Monod limitation }\end{array}$ \\
\hline$K_{\text {Feed,ZOO,Dipt }}\left(\mathrm{gDM} \mathrm{m}^{-3}\right)$ & 0.15 & $\begin{array}{l}\text { Threshold zooplankton concentration when diptera feeding switches } \\
\text { to linear dependence }\end{array}$ \\
\hline$K_{\mathrm{NO}_{3}, \text { miner }}\left(\mathrm{gN} \mathrm{m}^{-3}\right)$ & 0.02 & $\begin{array}{l}\text { Half-saturation nitrate concentration for anoxic mineralization; } \\
\text { Leads to a sharper transition between anoxic and anaerobic miner. }\end{array}$ \\
\hline$K_{O_{2}, \text { miner }}\left(\mathrm{gO} \mathrm{m}^{-3}\right)$ & 0.1 & $\begin{array}{l}\text { Half-saturation oxygen concentration for aerobic mineralization; } \\
\text { Leads to a sharper transition between aerobic and anoxic miner. }\end{array}$ \\
\hline$k_{\text {oxid }, \mathrm{CH}_{4}}\left(\mathrm{~m}^{3} \mathrm{gO}^{-1} \mathrm{~d}^{-1}\right)$ & 0.04 & Reaction velocity of methane oxidation \\
\hline$k_{r e s p, Z O O, T_{0}}\left(\mathrm{~d}^{-1}\right)$ & 0.01 & $\begin{array}{l}\text { Respiration rate coefficient of zooplankton; more realistic including } \\
\text { Planktothrix rubescens }\end{array}$ \\
\hline$k_{u p t, X_{I}}\left(\mathrm{~m}^{3} \mathrm{gDM}^{-1} \mathrm{~d}^{-1}\right)$ & 30 & Maximum uptake rate of phosphate uptake on inert particles \\
\hline$K_{z, \text { summer }} / K_{z, \text { winter }}\left(\mathrm{m}^{2} \mathrm{~d}^{-1}\right)$ & $*$ & Coefficient of vertical turbulent diffusion in the metalimnion \\
\hline$p_{N_{4}, A L G}$ & 10 & Preference factor of phytoplankton growth on ammonium \\
\hline tempdif $\left({ }^{\circ} \mathrm{C}\right)$ & $*$ & $\begin{array}{l}\text { Temperature difference between epi- and hypolimnion; } \\
\text { Switching between summer and winter mixing }\end{array}$ \\
\hline$v_{\mathrm{CH}_{4}, \text { atm }}\left(\mathrm{m} \mathrm{d}^{-1}\right)(\mathrm{gre} / \mathrm{wal} / \mathrm{zh})$ & $0.5 / 3 / 1$ & Methane exchange velocity with atmosphere, according to oxygen \\
\hline$v_{O_{2}, a t m}\left(\mathrm{~m} \mathrm{~d}^{-1}\right)$ (gre/wal/zh) & $0.5 / 3 / 1$ & $\begin{array}{l}\text { Oxygen exchange velocity with atmosphere, differing by specific } \\
\text { wind speed }\end{array}$ \\
\hline$v_{\text {sed }, A L G}\left(\mathrm{~m} \mathrm{~d}^{-1}\right)$ & 0.1 & $\begin{array}{l}\text { Sedimentation velocity of phytoplankton; } \\
\text { better approximation for aggregated plankton model }\end{array}$ \\
\hline$v_{u p, Z O O}\left(\mathrm{~m} \mathrm{~d}^{-1}\right)$ & 5 & Upwards velocity of zooplankton \\
\hline
\end{tabular}


Table 2: Description and prior marginals of the calibrated parameters of the deterministic model and the error model.

\begin{tabular}{|c|c|c|c|c|c|}
\hline Name & Unit & Distribution & Mean & StDev & Description \\
\hline $\begin{array}{l}f_{X_{I}, \text { rivers }} \\
\text { (transformed) }\end{array}$ & - & Normal & 2 & 1 & $\begin{array}{l}\text { Inert fraction of allochthonous } \\
\text { organic particles }\end{array}$ \\
\hline$k_{\text {death }, A L G, T_{0}}$ & $d^{-1}$ & Lognormal & 0.0721 & 0.05 & $\begin{array}{l}\text { Death rate of phytoplankton at } \\
\text { reference temperature }\end{array}$ \\
\hline$k_{\text {death }, Z O O, T_{0}, g r e}$ & $d^{-1}$ & Lognormal & 0.0675 & 0.05 & $\begin{array}{l}\text { Death rate of zooplankton at } \\
\text { reference temperature (Greifensee) }\end{array}$ \\
\hline$k_{\text {death }, Z O O, T_{0}, \text { wal }}$ & $d^{-1}$ & Lognormal & 0.0432 & 0.05 & $\begin{array}{l}\text { Death rate of zooplankton at } \\
\text { reference temperature (Walensee) }\end{array}$ \\
\hline$k_{\text {death }, Z O O, T_{0}, z h}$ & $d^{-1}$ & Lognormal & 0.0675 & 0.05 & $\begin{array}{l}\text { Death rate of zooplankton at } \\
\text { reference temperature (Lake Zurich) }\end{array}$ \\
\hline$K_{\text {Feed }}$ & $\mathrm{gDM} \mathrm{m}^{-3}$ & Lognormal & 0.295 & 0.3 & $\begin{array}{l}\text { Threshold phytoplankton } \\
\text { concentration when zooplankton } \\
\text { feeding switches to Monod limit. }\end{array}$ \\
\hline$k_{g r o, A L G, T_{0}, I_{0}}$ & $d^{-1}$ & Lognormal & 1.79 & 0.5 & $\begin{array}{l}\text { Growth rate of phytoplankton at } \\
\text { reference temp./sat. light intensity }\end{array}$ \\
\hline$k_{g r o, Z O O, T_{0}}$ & $d^{-1}$ & Lognormal & 0.397 & 0.25 & $\begin{array}{l}\text { Growth rate of zooplankton at } \\
\text { reference temperature }\end{array}$ \\
\hline$k_{\text {miner }, \text { aero, sed }, T_{0}, \text { gre }}$ & $d^{-1}$ & Lognormal & 0.365 & 0.25 & $\begin{array}{l}\text { Aerobic mineralization rate at } \\
\text { reference temperature (Greifensee) }\end{array}$ \\
\hline$k_{\text {miner }, \text { aero }, \text { sed }, T_{0}, \text { wal }}$ & $d^{-1}$ & Lognormal & 0.063 & 0.05 & $\begin{array}{l}\text { Aerobic mineralization rate at } \\
\text { reference temperature (Walensee) }\end{array}$ \\
\hline$k_{\text {miner }, \text { aero }, \text { sed }, T_{0}, z h}$ & $d^{-1}$ & Lognormal & 0.295 & 0.3 & $\begin{array}{l}\text { Aerobic mineralization rate at } \\
\text { reference temperature (Lake Zurich) }\end{array}$ \\
\hline$k_{\text {miner }, \text { anae }, \text { sed }, T_{0}, \text { gre }}$ & $d^{-1}$ & Lognormal & 0.365 & 0.25 & $\begin{array}{l}\text { Anaerobic mineralization rate at } \\
\text { reference temperature (Greifensee) }\end{array}$ \\
\hline$k_{\text {miner }, \text { anae }, \text { sed }, T_{0}, \text { wal }}$ & $d^{-1}$ & Lognormal & 0.063 & 0.05 & $\begin{array}{l}\text { Anaerobic mineralization rate at } \\
\text { reference temperature (Walensee) }\end{array}$ \\
\hline$k_{\text {miner }, \text { anae }, \text { sed }, T_{0}, z h}$ & $d^{-1}$ & Lognormal & 0.295 & 0.3 & $\begin{array}{l}\text { Anaerobic mineralization rate at } \\
\text { reference temperature (Lake Zurich) }\end{array}$ \\
\hline$k_{\text {miner }, \text { anox }, \text { sed }, T_{0}, \text { gre }}$ & $d^{-1}$ & Lognormal & 0.365 & 0.25 & $\begin{array}{l}\text { Anoxic mineralization rate at } \\
\text { reference temperature (Greifensee) }\end{array}$ \\
\hline$k_{\text {miner }, \text { anox }, \text { sed }, T_{0}, \text { wal }}$ & $d^{-1}$ & Lognormal & 0.063 & 0.05 & $\begin{array}{l}\text { Anoxic mineralization rate at } \\
\text { reference temperature (Walensee) }\end{array}$ \\
\hline$k_{\text {miner }, \text { anox }, \text { sed }, T_{0}, z h}$ & $d^{-1}$ & Lognormal & 0.295 & 0.3 & $\begin{array}{l}\text { Anoxic mineralization rate at } \\
\text { reference temperature (Lake Zurich) }\end{array}$ \\
\hline$\sigma_{\mathrm{B}, \mathrm{ALG}}$ & $\mathrm{gWM}^{1 / 2} \mathrm{~m}^{-3 / 2}$ & Exponential & 0.3 & & $\begin{array}{l}\text { Standard deviation of bias in } \\
\text { phytoplankton }\end{array}$ \\
\hline$\sigma_{\mathrm{B}, \mathrm{HPO}_{4}}$ & $\mathrm{gP}^{1 / 2} \mathrm{~m}^{-3 / 2}$ & Exponential & 0.035 & & $\begin{array}{l}\text { Standard deviation of bias in } \\
\text { phosphate }\end{array}$ \\
\hline$\sigma_{\mathrm{B}, \mathrm{NO}_{3}}$ & $\mathrm{gN}^{1 / 2} \mathrm{~m}^{-3 / 2}$ & Exponential & 0.05 & & Standard deviation of bias in nitrate \\
\hline$\sigma_{\mathrm{B}, \mathrm{O}_{2}}$ & $\mathrm{gO}^{1 / 2} \mathrm{~m}^{-3 / 2}$ & Exponential & 0.5 & & Standard deviation of bias in oxygen \\
\hline$\sigma_{\mathrm{B}, \mathrm{ZOO}}$ & $\mathrm{gWM}^{1 / 2} \mathrm{~m}^{-3 / 2}$ & Exponential & 0.4 & & $\begin{array}{l}\text { Standard deviation of bias in } \\
\text { zooplankton }\end{array}$ \\
\hline
\end{tabular}




\begin{tabular}{|lclccl|}
\hline$\sigma_{\mathrm{E}, \mathrm{ALG}}$ & $\mathrm{gWM}^{1 / 2} \mathrm{~m}^{-3 / 2}$ & Lognormal & 0.07 & 0.02 & $\begin{array}{l}\text { Standard deviation of measurement } \\
\text { error in phytoplankton }\end{array}$ \\
$\sigma_{\mathrm{E}, \mathrm{HPO} \mathrm{H}_{4}}$ & $\mathrm{gP}^{1 / 2} \mathrm{~m}^{-3 / 2}$ & Lognormal & 0.007 & 0.0002 & $\begin{array}{l}\text { Standard deviation of measurement } \\
\text { error in phosphate }\end{array}$ \\
$\sigma_{\mathrm{E}, \mathrm{NO}_{3}}$ & $\mathrm{gN}^{1 / 2} \mathrm{~m}^{-3 / 2}$ & Lognormal & 0.022 & 0.002 & $\begin{array}{l}\text { Standard deviation of measurement } \\
\text { error in nitrate }\end{array}$ \\
$\sigma_{\mathrm{E}, \mathrm{O}_{2}}$ & $\mathrm{gO}^{1 / 2} \mathrm{~m}^{-3 / 2}$ & Lognormal & 0.11 & 0.01 & $\begin{array}{l}\text { Standard deviation of measurement } \\
\text { error in oxygen }\end{array}$ \\
$\sigma_{\mathrm{E}, \mathrm{ZOO}}$ & $\mathrm{gWM}^{1 / 2} \mathrm{~m}^{-3 / 2}$ & Lognormal & 0.08 & 0.02 & $\begin{array}{l}\text { Standard deviation of measurement } \\
\text { error in zooplankton }\end{array}$ \\
\hline
\end{tabular}

Table 3: Results of the joint sensitivity analysis for all three lakes

\begin{tabular}{|c|c|c|c|c|c|}
\hline Parameter & $\delta_{\theta_{j}}^{m s q r}$ & $\begin{array}{l}\text { Parameter } \\
\text { (continued) }\end{array}$ & $\delta_{\theta_{j}}^{m s q r}$ & $\begin{array}{l}\text { Parameter } \\
\text { (continued) }\end{array}$ & $\delta_{\theta_{j}}^{m s q r}$ \\
\hline$K_{z, \text { summer,gre }}$ & 10.520 & $h_{\text {sed }_{1}, z h}$ & 0.888 & $v_{O_{2}, \text { atm,gre }}$ & 0.116 \\
\hline$K_{\text {Feed }}$ & 9.562 & $h_{\text {sed }_{1}, \text { gre }}$ & 0.774 & $K_{z, \text { summer,wal }}$ & 0.105 \\
\hline$k_{g r o, A L G, T_{0}, I_{0}}$ & 7.967 & $h_{\text {sed }_{2}, \text { gre }}$ & 0.756 & $K_{z, \text { winter,gre }}$ & 0.104 \\
\hline$K_{z, \text { winter }, z h}$ & 7.024 & $b_{P, \min }$ & 0.707 & $D_{O_{2}}$ & 0.101 \\
\hline$w_{Z O O}$ & 5.701 & $a_{P, \max , X_{I}}$ & 0.625 & $k_{\text {miner,anae,sed, } T_{0}, \text { wal }}$ & 0.093 \\
\hline$K_{I, A L G}$ & 4.450 & $v_{\text {sed }, O R G}$ & 0.571 & $k_{u p t, X_{S}, w a l}$ & 0.066 \\
\hline$K_{z, \text { summer }, z h}$ & 4.236 & $c_{e}$ & 0.548 & $v_{O_{2}, a t m, z h}$ & 0.062 \\
\hline$k_{\text {death }, Z O O, T_{0}, z h}$ & 4.159 & $f_{X_{I}, \text { rivers }}$ & 0.544 & $k_{\text {miner, anae }, \text { sed }, T_{0}, z h}$ & 0.057 \\
\hline tempdif $_{z h}$ & 4.059 & $a_{P, \text { inflow }}$ & 0.463 & $K_{\mathrm{NO}_{3}, \text { miner }}$ & 0.048 \\
\hline$k_{\text {death, } A L G, T_{0}}$ & 3.891 & $w_{O R G}$ & 0.427 & $k_{\text {nitri }, \text { wat }, T_{0}}$ & 0.044 \\
\hline$v_{u p, Z O O}$ & 3.747 & $k_{\text {miner, aero, }, \text { sed }, T_{0}, \text { wal }}$ & 0.360 & $k_{\text {upt }, X_{I}, \text { wal }}$ & 0.043 \\
\hline$K_{A L G, Z O O}$ & 3.725 & $k_{\text {upt }, X_{S}, \text { gre }}$ & 0.350 & $k_{\text {deat }, Z O O, T_{0}, \text { wal }}$ & 0.040 \\
\hline$b_{P, \max }$ & 3.541 & $h_{\text {sed }_{1}, w a l}$ & 0.287 & $k_{\text {miner }, \text { aero, wat }, T_{0}}$ & 0.035 \\
\hline$k_{r e s p, A L G, T_{0}}$ & 3.210 & $\beta_{B A C}$ & 0.287 & $a_{C}$ & 0.033 \\
\hline$f_{\text {sol }}$ & 3.143 & $h_{\text {sed }_{2}, w a l}$ & 0.265 & $p_{A L G, N H_{4}}$ & 0.032 \\
\hline$k_{g r o, Z O O, T_{0}}$ & 2.895 & $K_{N, A L G}$ & 0.260 & $k_{\text {upt }, X_{I}, g r e}$ & 0.031 \\
\hline$k_{\text {death }, Z O O, T_{0}, g r e}$ & 2.816 & $K_{\mathrm{O}_{2}, \text { resp }}$ & 0.247 & $K_{O_{2}, a d s}$ & 0.024 \\
\hline$f_{p}$ & 2.648 & $k_{\text {miner, anae, sed }, T_{0}, \text { gre }}$ & 0.241 & $k_{u p t, X_{I}, z h}$ & 0.022 \\
\hline$\beta_{\text {ZOO }}$ & 2.534 & $k_{u p t, X_{S}, z h}$ & 0.235 & $k_{o x i d, C H_{4}}$ & 0.022 \\
\hline tempdif $_{g r e}$ & 2.404 & $K_{O_{2}, \text { miner }}$ & 0.230 & $k_{\text {nitri }, \text { sed }, T_{0}}$ & 0.017 \\
\hline$\beta_{A L G}$ & 2.151 & $K_{z, \text { winter,wal }}$ & 0.217 & $k_{\text {miner }, \text { anox }, \text { wat }, T_{0}}$ & 0.012 \\
\hline$k_{r e s p, Z O O, T_{0}}$ & 2.100 & $k_{\text {miner }, \text { aero }, \text { sed }, T_{0}, z h}$ & 0.207 & $K_{O_{2}, n i t r i}$ & 0.012 \\
\hline$K_{H P O_{4}, A L G}$ & 1.695 & $a_{P, \max , X_{S}}$ & 0.206 & $v_{O_{2}, a t m, w a l}$ & 0.012 \\
\hline
\end{tabular}




\begin{tabular}{|c|c|c|c|c|c|}
\hline$v_{\text {sed }, A L G}$ & 1.614 & $k_{\text {miner, anox,sed }, T_{0}, \text { gre }}$ & 0.197 & $k_{\text {miner,anae, wat }, T_{0}}$ & 0.011 \\
\hline$f_{\text {porgpart }}$ & 1.597 & $k_{\text {miner, aero,sed }, T_{0}, \text { gre }}$ & 0.179 & $v_{\text {sed,INORG }}$ & 0.009 \\
\hline$\theta$ & 1.518 & $h_{\text {sed }_{2}, z h}$ & 0.178 & $D_{C_{4}}$ & 0.009 \\
\hline$f_{X_{I}, \text { lake }}$ & 1.472 & $a_{N}$ & 0.157 & $v_{C H_{4}, a t m, z h}$ & 0.007 \\
\hline$S_{\mathrm{HPO}_{4}, \text { crit }}$ & 1.100 & $D_{\mathrm{NO}_{3}}$ & 0.154 & $v_{\mathrm{CH}_{4}, \mathrm{~atm}, \mathrm{wal}}$ & 0.004 \\
\hline tempdif $_{w a l}$ & 1.078 & $k_{\text {miner, anox }, \text { sed }, T_{0}, z h}$ & 0.152 & $v_{C_{4}, \text { atm,gre }}$ & 0.003 \\
\hline$a_{P, \text { inflow,lake }}$ & 0.902 & $k_{\text {miner, anox }, \text { sed }, T_{0}, \text { wal }}$ & 0.144 & & \\
\hline$w_{A L G}$ & 0.894 & $K_{O_{2}, \text { ZOO }}$ & 0.137 & & \\
\hline
\end{tabular}

Table 4: Estimated values of parameters used for automatic calibration.

\begin{tabular}{|c|c|c|c|c|c|}
\hline Name (Unit) & Value & Name (Unit) & Value & Name (Unit) & Value \\
\hline$f_{X_{I}, \text { rivers }}(-)$ & 0.932 & $k_{\text {miner }, \text { aer }, \text { sed }, T_{0}, \text { gre }}\left(\mathrm{d}^{-1}\right)$ & 0.161 & $\sigma_{\mathrm{B}, \mathrm{ALG}}\left(\mathrm{gWM}^{1 / 2} \mathrm{~m}^{-3 / 2}\right)$ & 0.622 \\
\hline$k_{\text {death, } A L G, T_{0}}\left(\mathrm{~d}^{-1}\right)$ & 0.046 & $k_{\text {miner,aero, }, \text { sed }, T_{0}, \text { wal }}\left(\mathrm{d}^{-1}\right)$ & 0.018 & $\sigma_{\mathrm{B}, \mathrm{HPO}}\left(\mathrm{gP}^{1 / 2} \mathrm{~m}^{-3 / 2}\right)$ & 0.126 \\
\hline$k_{\text {death }, Z O O, T_{0}, \text { gre }}\left(\mathrm{d}^{-1}\right)$ & 0.119 & $k_{\text {miner, aero }, \text { sed }, T_{0}, z h}\left(\mathrm{~d}^{-1}\right)$ & 0.116 & $\sigma_{\mathrm{B}, \mathrm{NO}_{3}}\left(\mathrm{gN}^{1 / 2} \mathrm{~m}^{-3 / 2}\right)$ & 0.121 \\
\hline$k_{\text {death }, Z O O, T_{0}, \text { wal }}\left(\mathrm{d}^{-1}\right)$ & 0.001 & $k_{\text {miner }, \text { anae }, \text { sed }, T_{0}, \text { gre }}\left(\mathrm{d}^{-1}\right)$ & 0.668 & $\sigma_{\mathrm{B}, \mathrm{O}_{2}}\left(\mathrm{gO}^{1 / 2} \mathrm{~m}^{-3 / 2}\right)$ & 0.499 \\
\hline$k_{\text {death }, Z O O, T_{0}, z h}\left(\mathrm{~d}^{-1}\right)$ & 0.014 & $k_{\text {miner,anae, sed }, T_{0}, \text { wal }}\left(\mathrm{d}^{-1}\right)$ & 0.011 & $\sigma_{\mathrm{B}, \mathrm{ZOO}}\left(\mathrm{gWM}^{1 / 2} \mathrm{~m}^{-3 / 2}\right)$ & 1.093 \\
\hline$K_{\text {Feed }}\left(\mathrm{gDM} \mathrm{m}^{-3}\right)$ & 0.945 & $k_{\text {miner }, \text { anae }, \text { sed }, T_{0}, z h}\left(\mathrm{~d}^{-1}\right)$ & 0.866 & $\sigma_{\mathrm{E}, \mathrm{ALG}}\left(\mathrm{gWM}^{1 / 2} \mathrm{~m}^{-3 / 2}\right)$ & 0.637 \\
\hline$k_{g r o, A L G, T_{0}, I_{0}}\left(\mathrm{~d}^{-1}\right)$ & 1.509 & $k_{\text {miner,anox }, \text { sed }, T_{0}, g r e}\left(\mathrm{~d}^{-1}\right)$ & 2.146 & $\sigma_{\mathrm{E}, \mathrm{HPO}_{4}}\left(\mathrm{gP}^{1 / 2} \mathrm{~m}^{-3 / 2}\right)$ & 0.013 \\
\hline \multirow[t]{3}{*}{$k_{g r o, Z O O, T_{0}}\left(\mathrm{~d}^{-1}\right)$} & 1.265 & $k_{\text {miner, anox,sed, } T_{0}, \text { wal }}\left(\mathrm{d}^{-1}\right)$ & 0.869 & $\sigma_{\mathrm{E}, \mathrm{NO}_{3}}\left(\mathrm{gN}^{1 / 2} \mathrm{~m}^{-3 / 2}\right)$ & 0.043 \\
\hline & & $k_{\text {miner, anox }, \text { sed }, T_{0}, z h}\left(\mathrm{~d}^{-1}\right)$ & 1.880 & $\sigma_{\mathrm{E}, \mathrm{O}_{2}}\left(\mathrm{gO}^{1 / 2} \mathrm{~m}^{-3 / 2}\right)$ & 0.210 \\
\hline & & & & $\sigma_{\text {E,ZOO }}\left(\mathrm{gWM}^{1 / 2} \mathrm{~m}^{-3 / 2}\right)$ & 0.660 \\
\hline
\end{tabular}




\section{Figures}

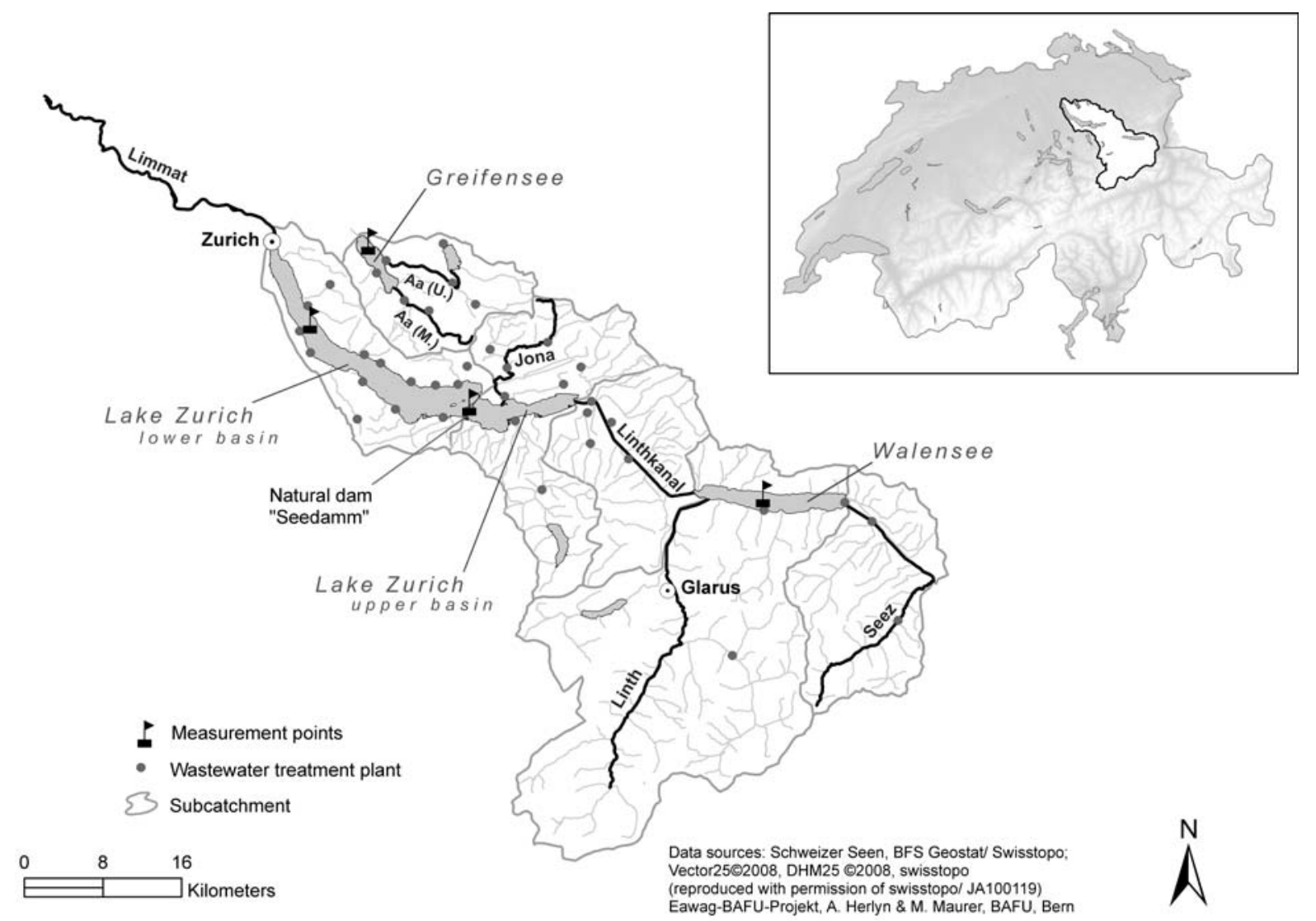

Figure 1: The three lakes, their catchments including the river network, the measurement stations, cities with relevant meteorological stations and the waste water treatment plants in the study area (actual situation 2011). 


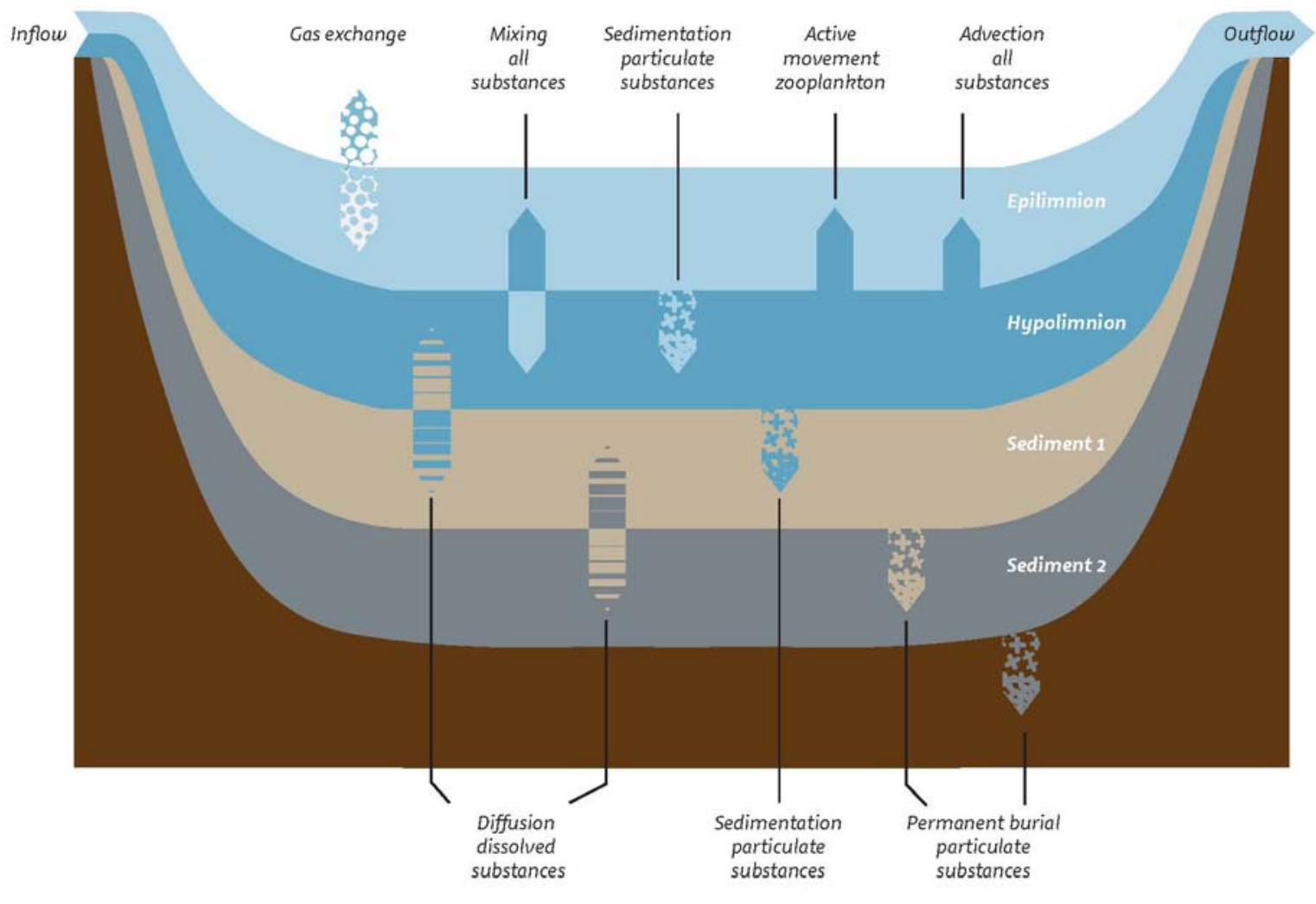

- infographic by Polyfahtor Designbüro -

Figure 2: Structure and physical processes of the four-box version of BELAMO. 


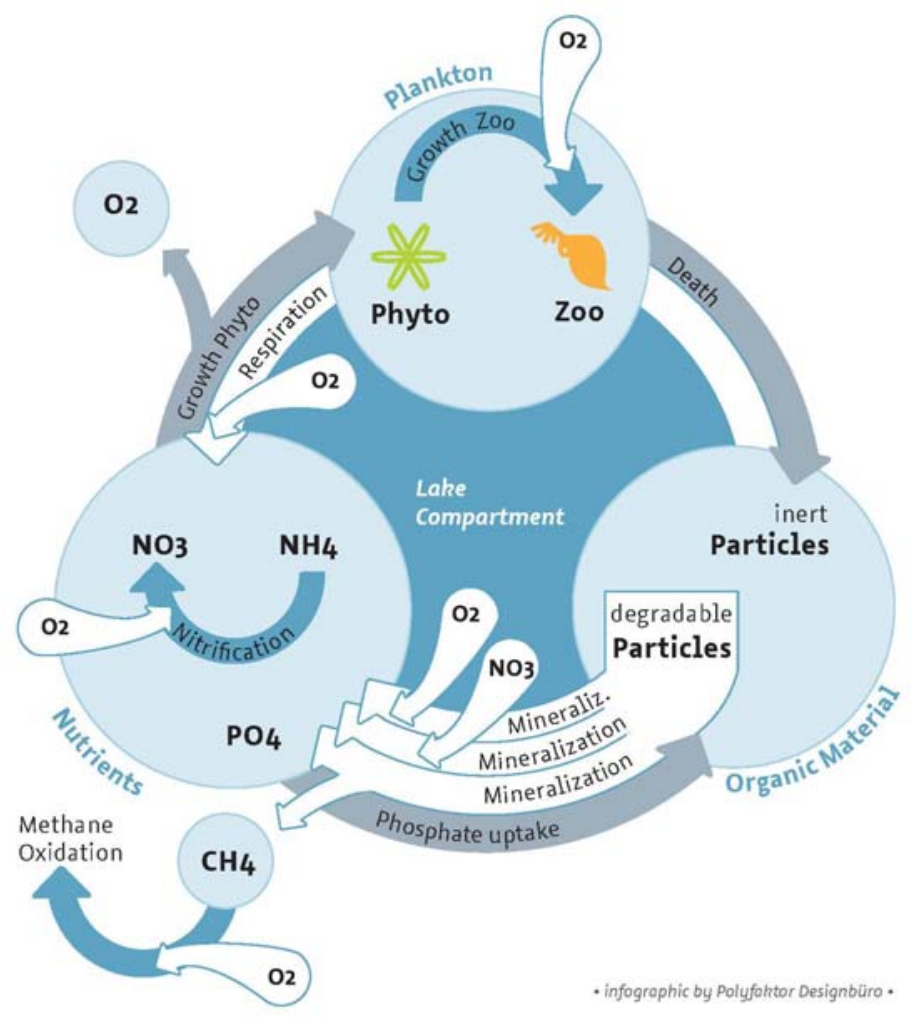

Figure 3: Biological and chemical processes taken into account in each of the model compartments of BELAMO. Some of them do not play a role in the sediment boxes and hence are not activated there. 

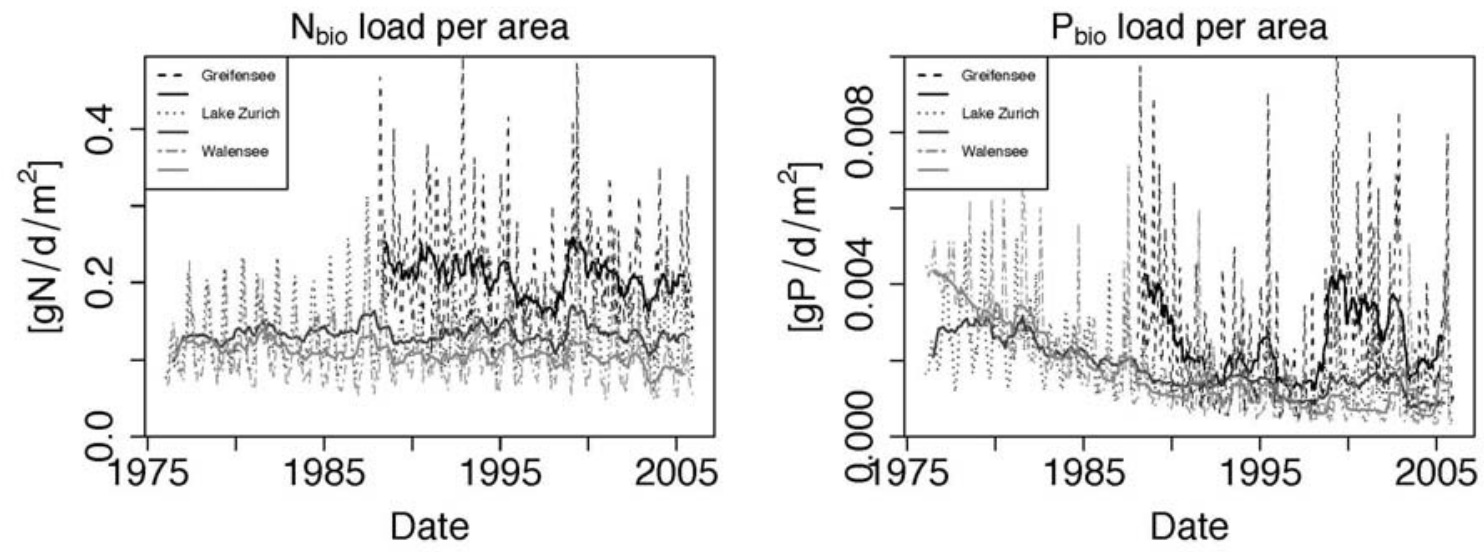

Figure 4: Input loads of bioavailable nitrogen and phosphorus per lake surface area. Dashed, dotted and dash-dotted lines indicate measured input data, bold lines their moving averages over 12 months. 

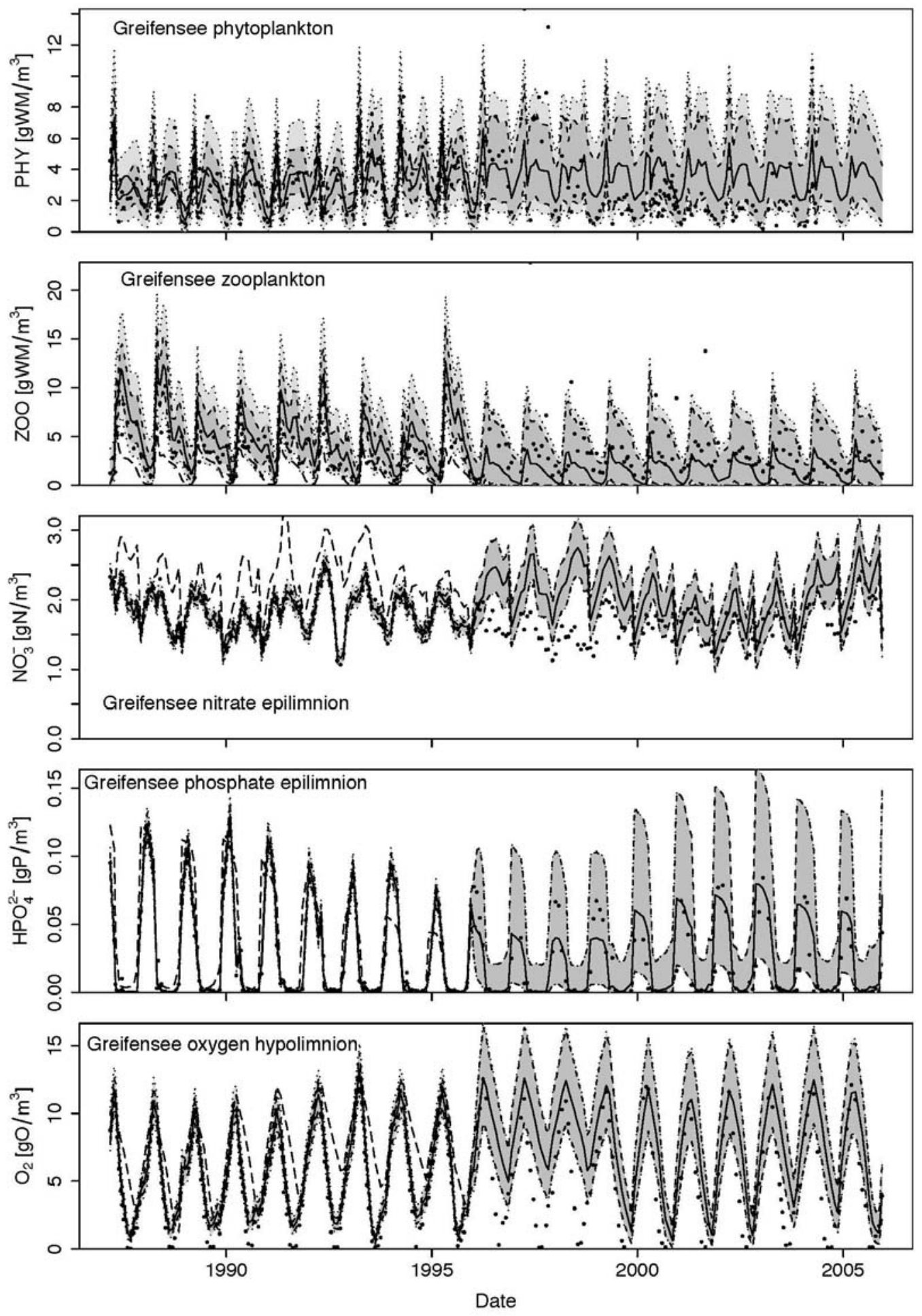

Figure 5: Phytoplankton (entire lake), zooplankton (entire lake), nitrate (epilimnion), phosphate (epilimnion) and oxygen (epilimnion) concentrations in Greifensee. Data points (markers), output of the deterministic model (long-dashed), median (solid) and 95\% credibility bounds (dark grey area with dashed boundaries) of bias-corrected output and median (solid; same as for bias-corrected output) and 95\%credibility bounds (dark and light grey areas with dotted boundaries) of predictions of new observations (including observation error). 

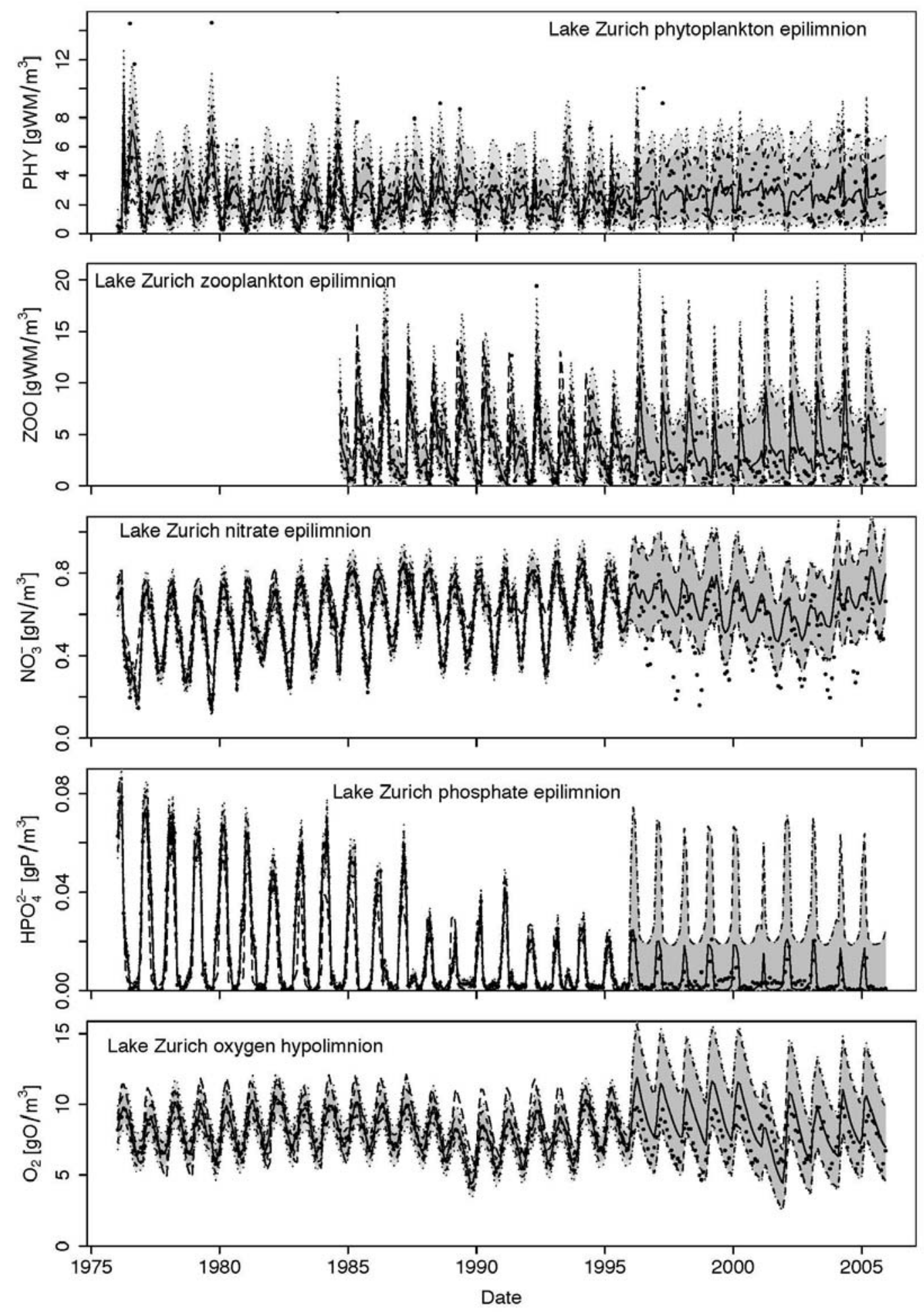

Figure 6: Phytoplankton, zooplankton, nitrate and phosphate concentrations in the epilimnion and oxygen concentrations in the hypolimnion of Lake Zurich. Data points (markers), output of the deterministic model (long-dashed), median (solid) and 95\%credibility bounds (dark grey area with dashed boundaries) of bias-corrected output and median (solid; same as for bias-corrected output) and 95\% credibility bounds (dark and light grey areas with dotted boundaries) of predictions of new observations (including observation error). 

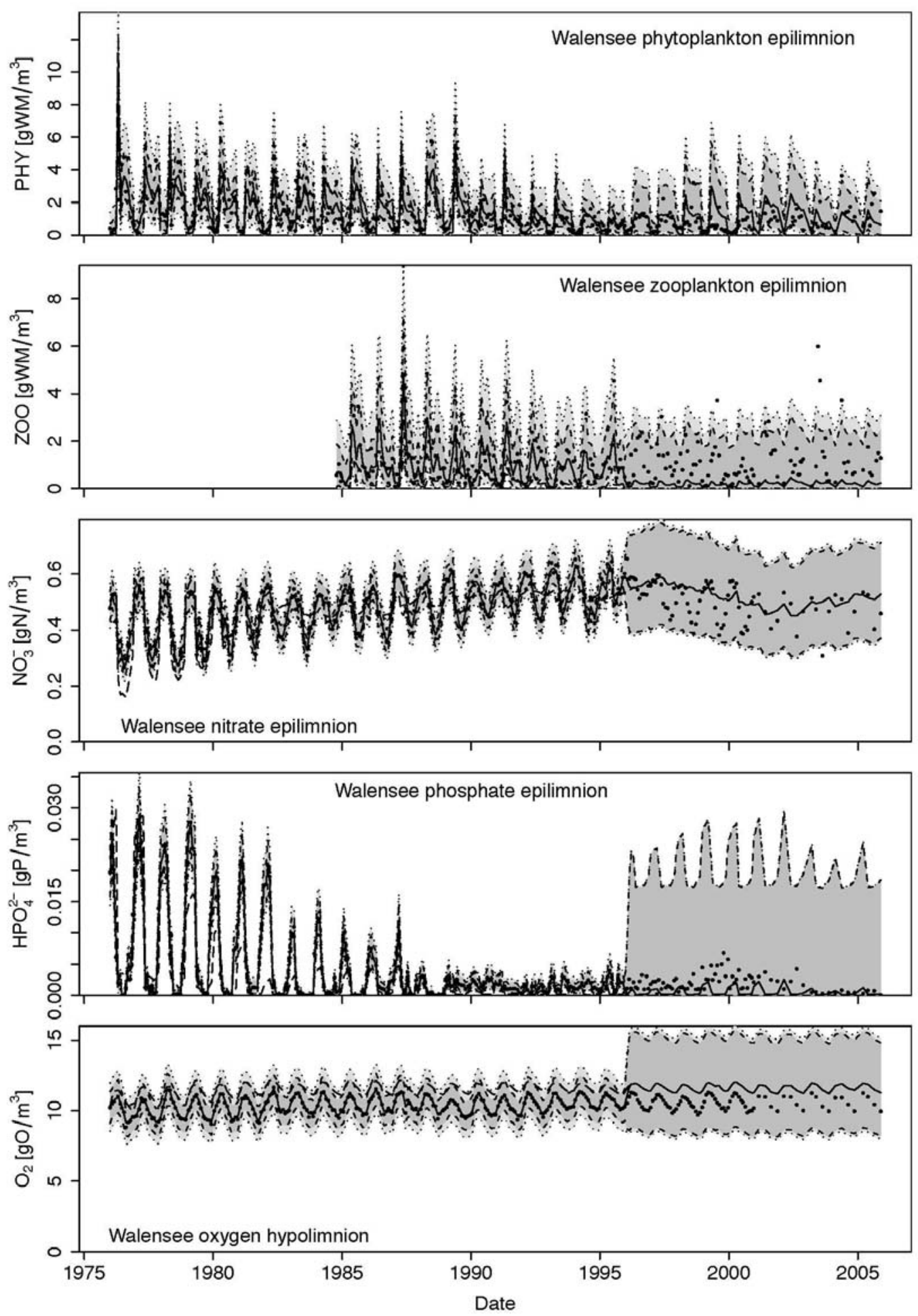

Figure 7: Phytoplankton, zooplankton, nitrate and phosphate concentrations in the epilimnion and oxygen concentrations in the hypolimnion of Walensee. Data points (markers), output of the deterministic model (long-dashed), median (solid) and 95\% credibility bounds (dark grey area with dashed boundaries) of bias-corrected output and median (solid; same as for bias-corrected output) and 95\% credibility bounds (dark and light grey areas with dotted boundaries) of predictions of new observations (including observation error). 
Greifensee / Lake Zurich / Walensee (in $\mathrm{N}_{\mathrm{bio}} / a$ )

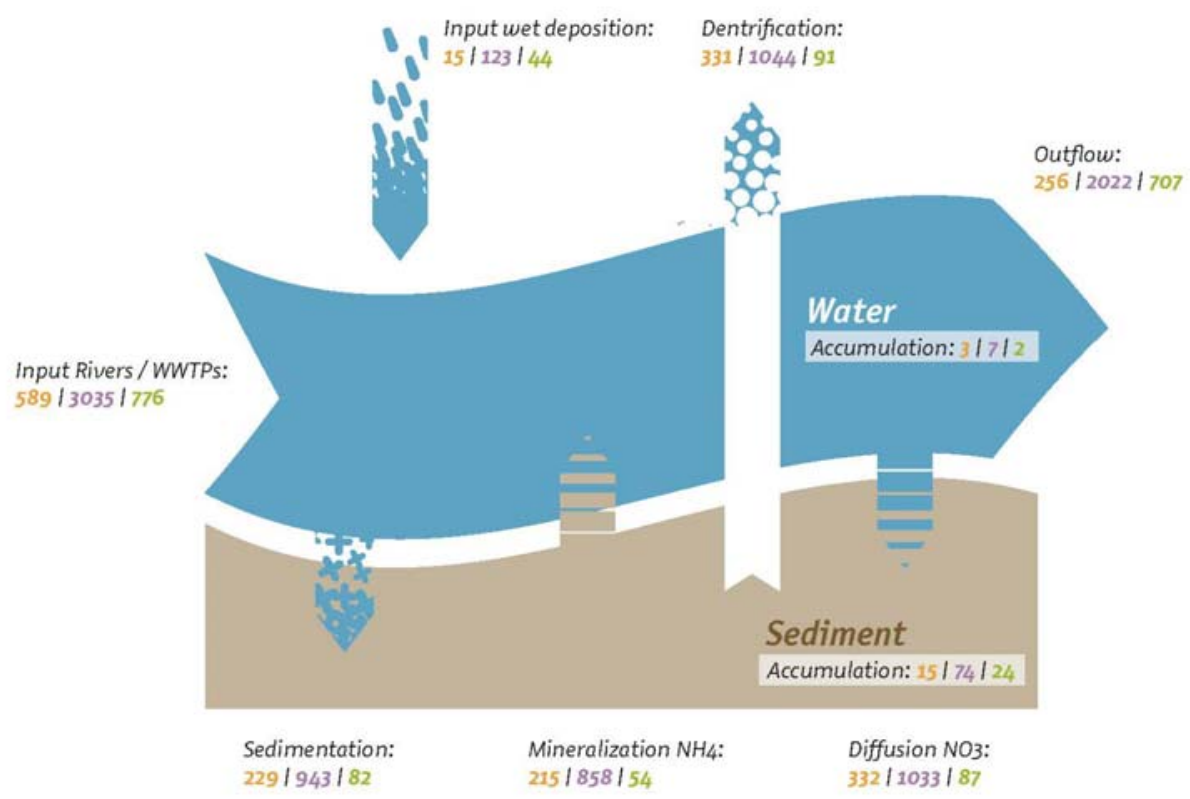

- infographic by Polyfahtor Designbüro .

Figure 8: Mass fluxes of bioavailable nitrogen in the water column and the sediment of Greifensee (left numbers), Lake Zurich (middle numbers) and Walensee (right numbers) in t/a (averaged over the 5 years 2001-2005) calculated with BELAMO. The errors for the overall mass balances are mostly around 1\%, at most $5 \%$. 


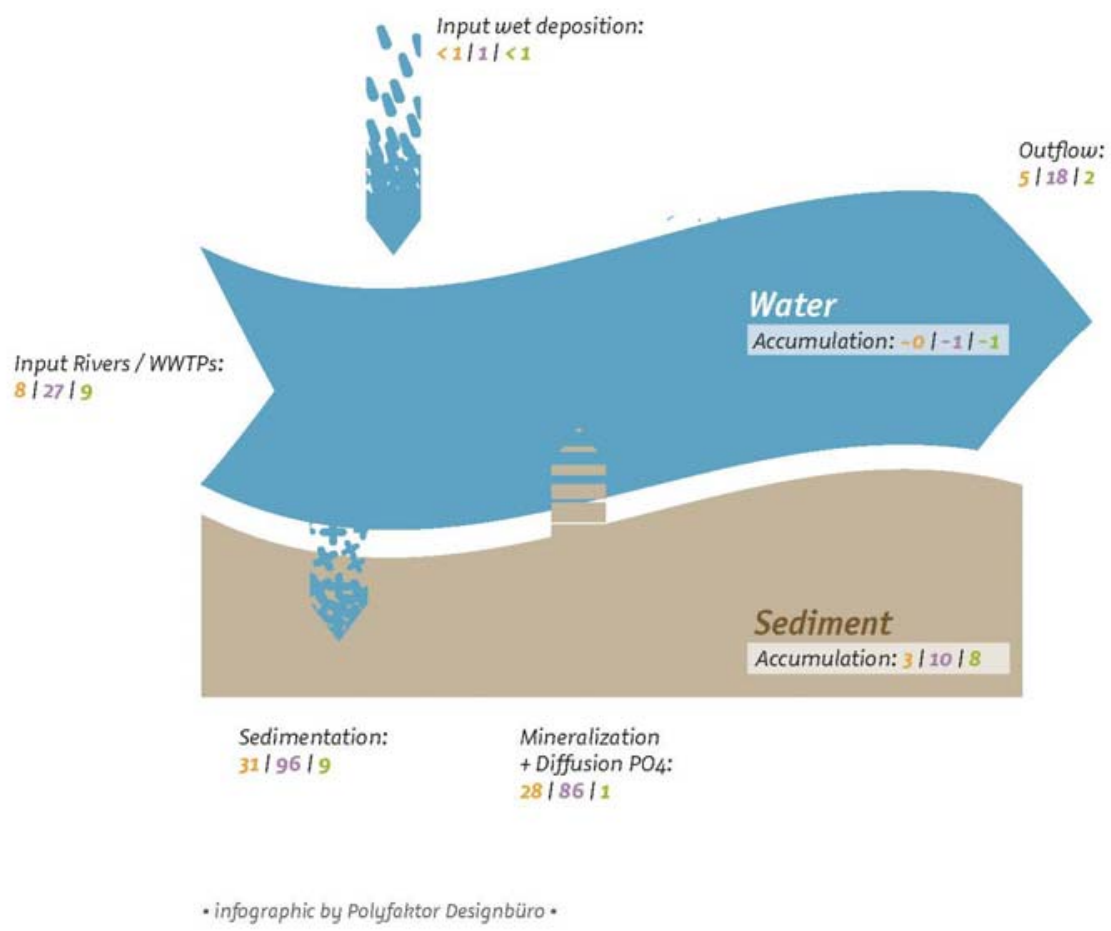

Figure 9: Mass fluxes of bioavailable phosphorus in the water column and the sediment of Greifensee (left numbers), Lake Zurich (middle numbers) and Walensee (right numbers) in t/a (averaged over the 5 years 2001-2005) calculated with BELAMO. The errors for the overall mass balances are mostly around $1 \%$, at most $5 \%$. 